\title{
Discursos y subjetividades en la Argentina actual
}

\author{
Alejandra Cebrelli, Daniel Rosso y Fabiana Martínez ${ }^{1}$ \\ Presentación: Alejandra Restagno
}

La segunda jornada del XX Congreso de REDCOM inició con el panel "Discursos y subjetividades en la Argentina actual" donde contamos con la presencia de los panelistas Alejandra Cebrelli de Salta, Daniel Rosso de Buenos Aires y Fabiana Martínez de Córdoba, quienes nos invitaron a transitar sobre profundos análisis en las discursividades actuales.

Centrada en el análisis de la imagen, Alejandra Cebrelli nos llevó a recorrer una fotogalería en la que ilustraba en tratamiento que los medios de comunicación realizaron durante las multitudinarias marchas a favor de la despenalización del aborto. La investigadora reconoce que se acerca a este objeto de estudio interesada en la performatividad de las marchas organizadas por el colectivo \#Ni una menos y \#8M, y que, a partir de allí, observa con ojo crítico y sensible el abordaje que se hizo desde los medios a los rostros y cuerpos femeninos durante el proceso de debate por la legalización del aborto.

En tanto que las investigaciones de Daniel Rosso y Fabiana Martínez tuvieron como eje el análisis de los discursos de Cambiemos y las subjetividades inscriptas en los mismos. Daniel Rosso analiza algunos spots publicitarios de Mauricio Macri que circularon en las redes sociales los cuáles hacen alusión a la capacidad individual de los sujetos emprendedores, hacedores y responsables de su puesto de trabajo mientras que el trabajo de Fabiana Martínez arroja luz sobre la construcción de la subjetividad meritocrática presente en los discursos del presidente y sus allegados.

En ambas investigaciones se abordan los análisis discursivos desde el concepto de pospolítica como campo donde circula el sentido poniendo énfasis en la construcción de subjetividades meritocráticas que fundamentan la desaparición de las políticas públicas como responsabilidad última del Estado legitimando la idea de responsabilidad individual de los sujetos sobre sus propios destinos.

1 La desgrabación del panel fue realizada por el Equipo de Comunicación del Instituto Académico Pedagógico de Ciencias Sociales y del EAS (Espacio Audiovisual Sociales). Agradecemos a Malvina Rodríguez y Paula Navarro las gestiones para poder compartir el panel en esta sección de REVCOM. 
Alejandra Cebrelli: Esta exposición se apoya en varias conferencias y trabajos publicados sobre las retóricas que construyen las organizaciones de mujeres al tomar la calle, durante las manifestaciones y cómo los medios realizan sus coberturas. He realizado investigaciones sobre varias marchas pero, en particular, hay una publicación, bastante larga hecha en una revista de La Plata, que tiene que ver con el $8 \mathrm{M}$ y que trabajé el año pasado. En ese momento yo estaba trabajando particularmente el discurso verbal y hoy voy a trabajar sobre las fotogalerías y, por supuesto, el debate. Entonces, ¿por qué me interesa esto? Ustedes saben que además yo estoy en una provincia que tiene el triste récord el año pasado de femicidios, de dos femicidios al mes; y tenemos este año el índice de abusos más alto del país. La violencia contra la mujer en mi provincia es un problema muy serio y sobre el cual hay que trabajar. Lo que fui observando es que, pese a todo lo que dicen los medios y lo que dicen los representantes del patriarcado, las marchas \#NiUnaMenos, las marchas multitudinarias sí tienen performatividad, es decir, sí tienen impacto sobre las prácticas cotidianas, inclusive en los lugares más vulnerables y más lejanos de las capitales, como por ejemplo en departamentos como Rivadavia en la provincia de Salta, que queda en la triple frontera, pobrísimo, devastado, donde hay comunidades originarias viviendo debajo de la línea de pobreza y, sin embargo, han sido capaces de protestar cuando ha habido casos de chineo que es una forma tradicional de abuso y de violaciones en banda que a veces llegan al femicidio, violaciones hechas por criollos a niñas muy chicas; nadie sabe nada de esto porque está totalmente invisibilizado. Esto es lo que me hizo poner la mirada no tanto en los encuentros nacionales de mujeres sino más en las marchas NiUnaMenos y $8 \mathrm{M}$ que van como incrementando el número de participantes hasta estallar en 2018.

Lo que hoy analizo para esta charla es el debate y la cobertura del debate en el Congreso Nacional a partir del proyecto de la ley IVE (Interrupción Voluntaria del Embarazo) redactado por la Campaña Nacional por el Derecho al Aborto Legal, Seguro y Gratuito.

Las mujeres hemos entendido que, si bien los medios funcionan como espejos deformantes de lo que sucede, también funcionan como amplificadores de las demandas y de los reclamos de género. Por lo tanto, tomar la calle, poner el cuerpo es una estrategia que obliga a las cámaras de los medios a focalizarse en estas protestas y, he podido observar, que las coberturas, tanto de medios de referencia nacional como de medios de referencia local, se van modificando según la convocatoria: si la convocatoria es masiva van a atenuar siempre 
REVCOM | ISSN 2451-7836 | Año 4, \#8 | mayo de 2019 | Encuentros | e005

(mientras dure la marcha) los valores patriarcales, que son feroces habitualmente y, sobre todo, en los medios concentrados.

Entonces, me interesa, cómo se va construyendo estas coberturas, qué tipo de retórica van a utilizar los medios para contar, mostrar qué sucedía en la calle mientras se daba el tratamiento de la ley en las dos cámaras.

¿Por qué me interesan estos dos casos? Porque reúnen lo que para la teoría del periodismo podríamos considerar, según la categoría de Fernández Pedemonte, un caso conmocionante, es decir, es un caso que, por alguna razón o no se había tratado nunca o la sociedad lo considera histórico; eso hace que la misma sociedad corte sus rutinas de consumo. Como los medios lo saben, alteran sus agendas y, mientras dure el interés, las agendas se van a modificar; inclusive muchas rutinas periodísticas van a ser cambiadas porque tienen que cubrir estás manifestaciones sí o sí.

Este tema se mantuvo en agenda permanente más de un mes.

Lo que podemos ver es que, en realidad, está la cobertura y la validación de la cobertura en fuerte relación con lo que está sucediendo y con lo que se percibía día a día como posible resultado de la votación de cada una de las cámaras. Entonces, vamos a ver que la atenuación en cuanto a los valores negativos (criminalización, por ejemplo) va a llegar incluso a una búsqueda de la neutralidad cuando se sabía que ganaban las verdes, cuando estaban a punto de hacerlo en Diputados.

A medida que nos vamos acercando al debate en Senadores, que es más conservador y patriarcal, empieza a aparecer nuevamente el discurso histórico que es siempre criminalizador de las mujeres, sobre todo de las feministas; $y$, de alguna forma, se llena de valores eufóricos el discurso de los autodenominados "Pro-vida".

Los trending topics dan cuenta de que \#EIAbortoSeráLey ocupó el primer puesto el 14 de junio y el segundo el 9 de agosto; lo que da cuenta de que realmente estuvo muy reñida esa elección.

Vamos a partir de algunas cuestiones que me parecen básicas: las mujeres en la calle (de todas estas indagaciones saqué algunas conclusiones) exhiben dos tipos de escritura: por un lado, en su propia piel y en el resto del cuerpo femenino, trayendo a modo de cartelería pero también a modo de espectralidad los cuerpos de las mujeres maltratadas, violentadas, en este caso se trata de las mujeres muertas o lesionadas por abortos clandestinos; éste es un 
REVCOM | ISSN 2451-7836 | Año 4, \#8 | mayo de 2019 | Encuentros | e005

mensaje que tiene que ver con la pedagogía de la crueldad, lo que está totalmente invisibilizado por los medios (a partir de este debate ya no tanto).

Por otro lado, la escritura que ellas hacen sobre sus propios cuerpos (se lo inscriben, se lo sobreinscriben, se ponen letreros en la cara), las pancartas que llevan, los cánticos que entonan y todos esos reclamos, son escrituras que se van sobreescribiendo una sobre la otra. Entonces, básicamente se lee una doble escritura, por un lado los cuerpos vulnerados, la escritura del patriarcado, de la pedagogía de la crueldad traída aunque sea de forma espectral o nominal y, por otro lado, una escritura absolutamente libertaria de estas mujeres que salen en la calle; entonces los cuerpos aparecen como signos ambiguos porque portan en sí mismos la contradicción entre modelos de mundos muy enfrentados: machismo-feminismo; los roles opuestos, la mujer como víctima pero aquí como una mujer guerrera; las manos que hacen el trazo de las escritura que son genéricamente diferenciadas, masculina y femenina, pero siempre inscriptas en el mismo significante que es el cuerpo de la mujer.

Por lo tanto, la figura que yo encuentro, la figura retórica a la base de esto, utilizando una categoría de Silvia Barei (que habla de un orden retórico; para ella el orden retórico es una especie de organización cultural de los discursos que utilizan ciertas figuras, ciertas estrategias para dar cuenta de las condiciones epocales, de lo que está pasando en una sociedad y en una época determinada), es el oxímoron y la otra figura que va a aparecer y se va a hacer cada vez más visible es la antítesis.

Me interesan porque en este evento están dando cuenta, por un lado, de dos posiciones totalmente enfrentadas pero violentamente enfrentadas: el patriarcado y las mujeres que nos alzamos cada vez con más fuerza y potencia ante ese patriarcado que, a su vez, reacciona, y eso produce una tensión polémica que se expresa tanto en el oxímoron como en la antítesis (que son dos figuras de la oposición, en realidad).

Lo que pasa es que esto se va a reduplicar, porque ¿cómo nos enteramos de esto? Si no vamos a las marchas, nos enteramos porque los medios reduplican esto y también lo hacen desde una escritura ambivalente porque los medios también tienen posiciones propias en relación al patriarcado, por lo tanto vuelven a reproducir tanto el oxímoron como la antítesis.

El oxímoron es una especie de cruz: una figura que contiene dos significados opuestos en el mismo significante.

íPara el corpus me metí en camisa de once varas porque no es exactamente lo mío, los discursos verbales, notas y crónicas periodísticas: en este caso son los registros fotográficos 
REVCOM | ISSN 2451-7836 | Año 4, \#8 | mayo de 2019 | Encuentros | e005

de los portales de los medios gráficos y online en circulación, particularmente de las veladas, pero no sólo de las veladas sino de las marchas de los días en los que se trató la ley en los dos congresos.

¿Por qué se me ocurrió tomar la fotografía y salirme del discurso verbal? Porque me parece que el fotoperiodismo tiene que ver con las formas de aparición y desaparición de la multitud de mujeres en el espacio público, qué se muestra y qué no. También, como diría DidiHuberman, las formas de exposición pero también de subexposición que construyen una política de la aparición de las diferencias en el espacio público y en el espacio mediático, en este caso, de género que significa: formas de ver, entender, vivir el género esta vez encarnado en cuerpos de mujer.

En cada cuerpo de mujer, femenino, pero también en los cuerpos disidentes hay una potencia referencial cuando un cuerpo se junta a otro cuerpo porque construye una zona visible para el medio y para la sociedad. La acumulación desbordante de cuerpos, que es lo que se ha dado en estas marchas, los cuerpos dicentes, no son cuerpos que solamente pasan, son cuerpos que dicen, y tienen esa potencialidad de que los medios lo tomen y lo lleven casi hasta el paroxismo, como sostiene Butler.

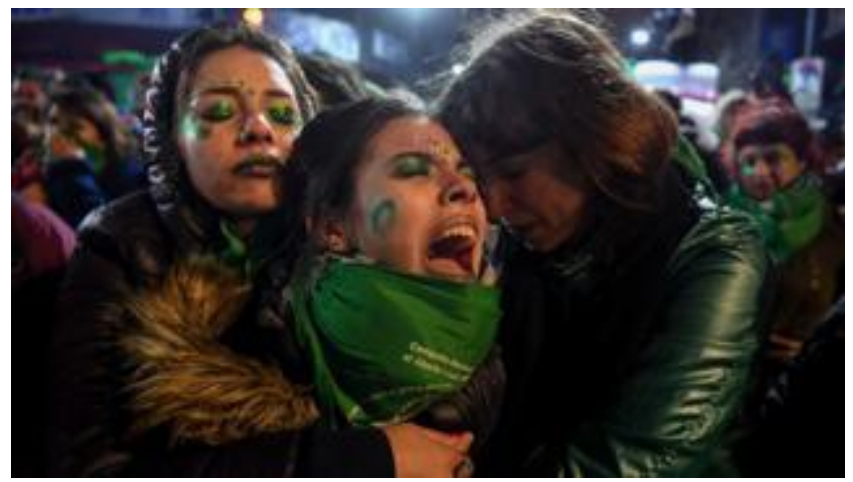

9 de agosto de 2018. https://www.bbc.com/mundo/noticias-america-latina-45137038

Estoy hablando, entonces, desde una perspectiva focalizada en el análisis del discurso de base semiológica, con algo de pragmática, en la semiótica de la cultura que es una de mis especialidades, pero también he recurrido a los aportes de la retórica clásica y de la retórica semiológica Grupo Mu. En tanto voy a trabajar con fotoperiodismo, dialogo con las teorías del periodismo. Obviamente están los estudios feministas de varias líneas y los estudios de fotografía y de la imagen. 
REVCOM | ISSN 2451-7836 | Año 4, \#8 | mayo de 2019 | Encuentros | e005

Entonces, la primera cuestión es que lo que más circuló fueron las fotos de la multitud; la multitud y la visibilidad; las fotos tomadas en drones. Esto estuvo en todos los medios y portales de circulación nacional, regional, internacional y local. Precisamente porque los cuerpos juntos tienen esta potencialidad referencial que es muy fuerte cuando son una multitud.
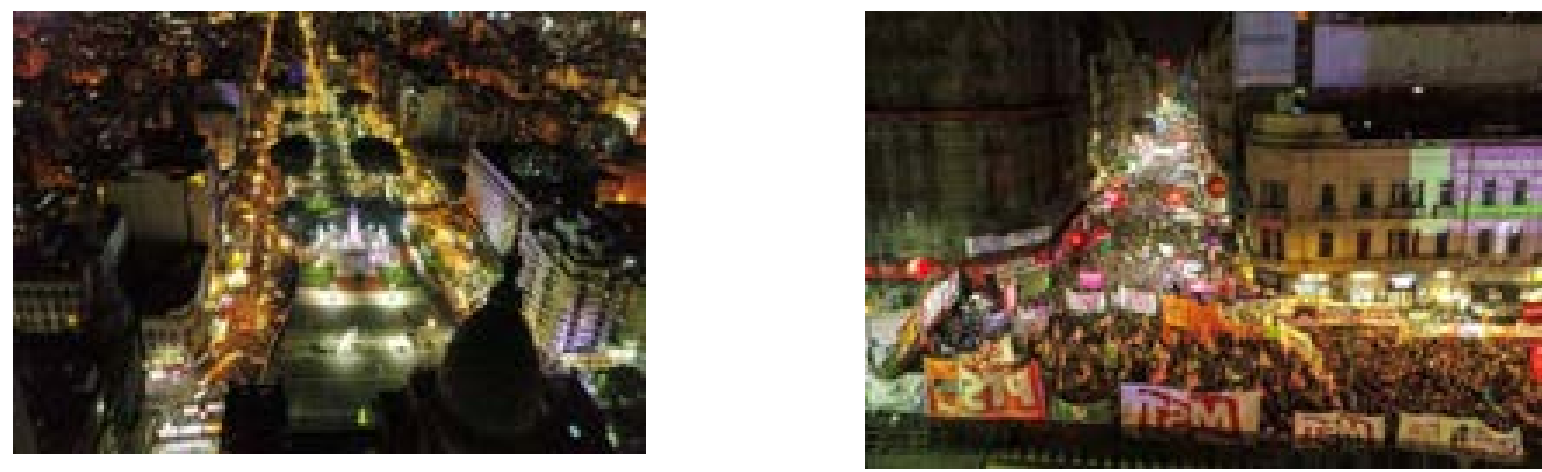

Fotogalería de clarín.com

Lo que vamos a ver acá, es que a lo largo de estas coberturas fotográficas hay como diversas políticas del encuadre, por parte del fotoperiodismo canónico. En el caso del alejamiento, hay un lugar de enunciación. ¿Por qué? Porque el medio aquí lo que hace jugar es la imposible objetividad porque es el equivalente del dato duro; la multitud puede "contarse" por cuadras, entonces crea el efecto de neutralidad que, sobre todo, es muy fuerte cuando empiezan estas marchas.

En relación a las representaciones emblemáticas como el pañuelo verde, también hay una cuestión a considerar: la fotografía se construye porque el fotografiado pone el cuerpo. El fotografiado se pone, sabe que lo están fotografiando y se pone de determinada manera y construye; este es un caso de construcción desde la militancia hacia el foco que los está registrando. $Y$ el pañuelo verde se torna un emblema para los que somos pro-Ley IVE y un estandarte; por eso empiezan a utilizarse los pañuelazos frente a todas las legislaturas o intendencias de pueblos y ciudades, porque esto pasó en todo el interior del país, aunque el trabajo se centre en el Congreso. La imagen de estos pañuelos al infinito funciona como una fuerte reiteración semántica y, al mismo tiempo, va a quedar como una especie de sinécdoque, o sea, la partecita por el todo, uno ve este pañuelo y sabe lo que significa; es como la pertenencia a estos movimientos feministas Pro Ley IVE. 


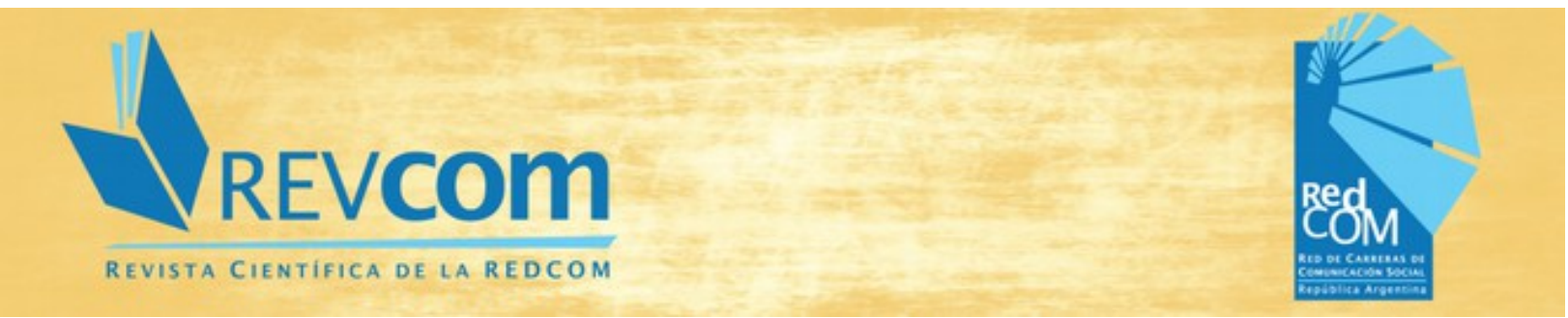

REVCOM | ISSN 2451-7836 | Año 4, \#8 | mayo de 2019 | Encuentros | e005

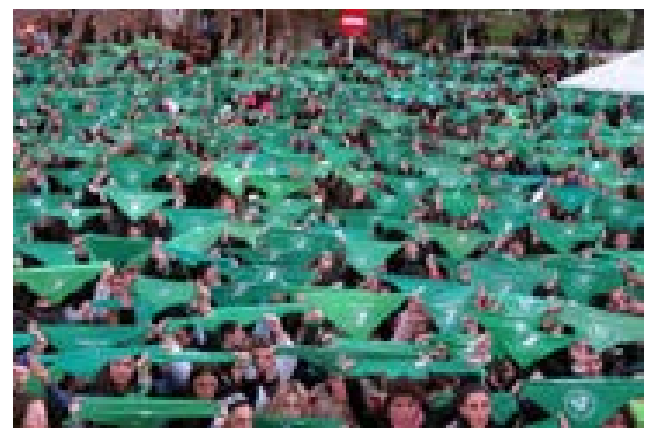

Esa intención del pañuelo, de llevarlo en la mochila, va semantizando los lugares y los espacios; entonces, se obliga a las cámaras de los medios a focalizar otras políticas del encuadre, no sólo el alejamiento, sino el primer plano, el plano detalle, que siempre va a resaltar el color verde.

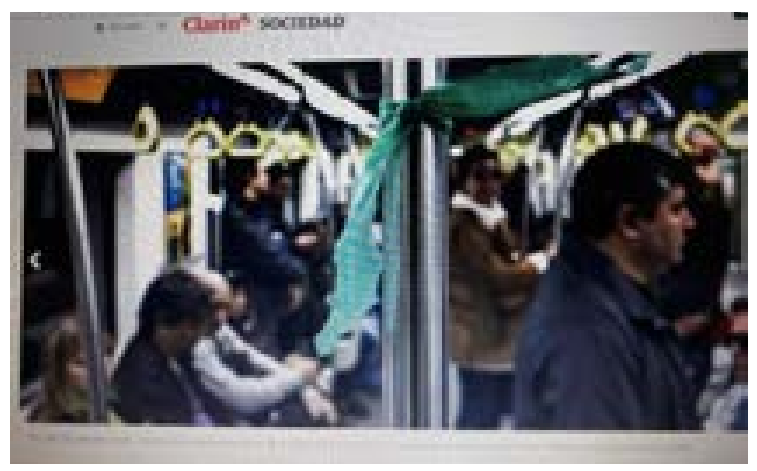

Fotogalería, clarín.com

Las mismos militantes van semantizando los espacios y la prensa utiliza la misma estrategia de semantización pero en la producción de sus fotografías.

La militancia registrada por el fotoperiodismo se ve en la Fotogalería clarin.com

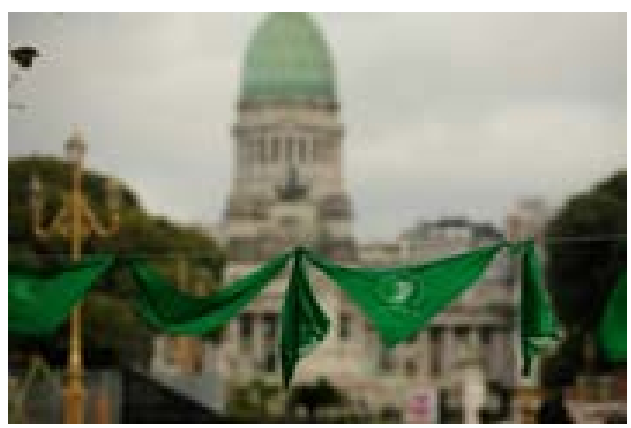




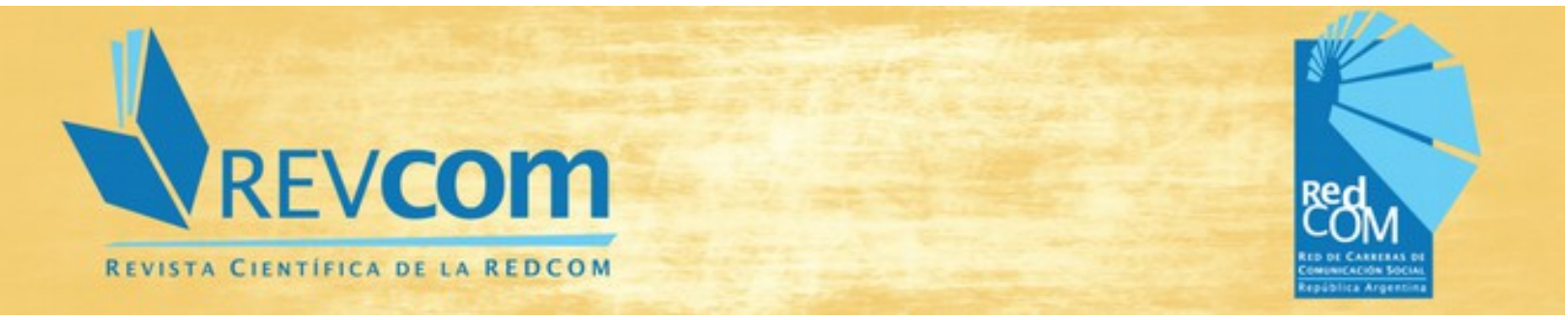

REVCOM | ISSN 2451-7836 | Año 4, \#8 | mayo de 2019 | Encuentros | e005

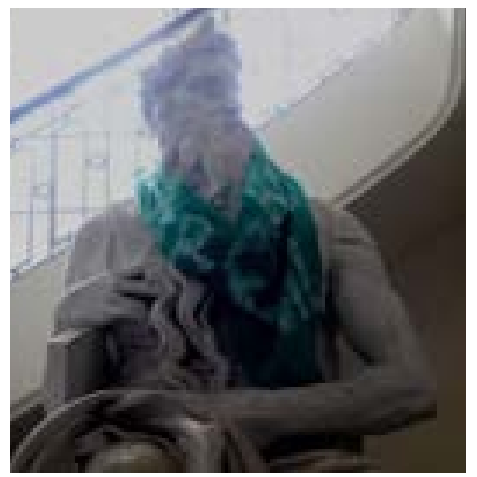

La contaminación icónica se produce en el mismo portal.
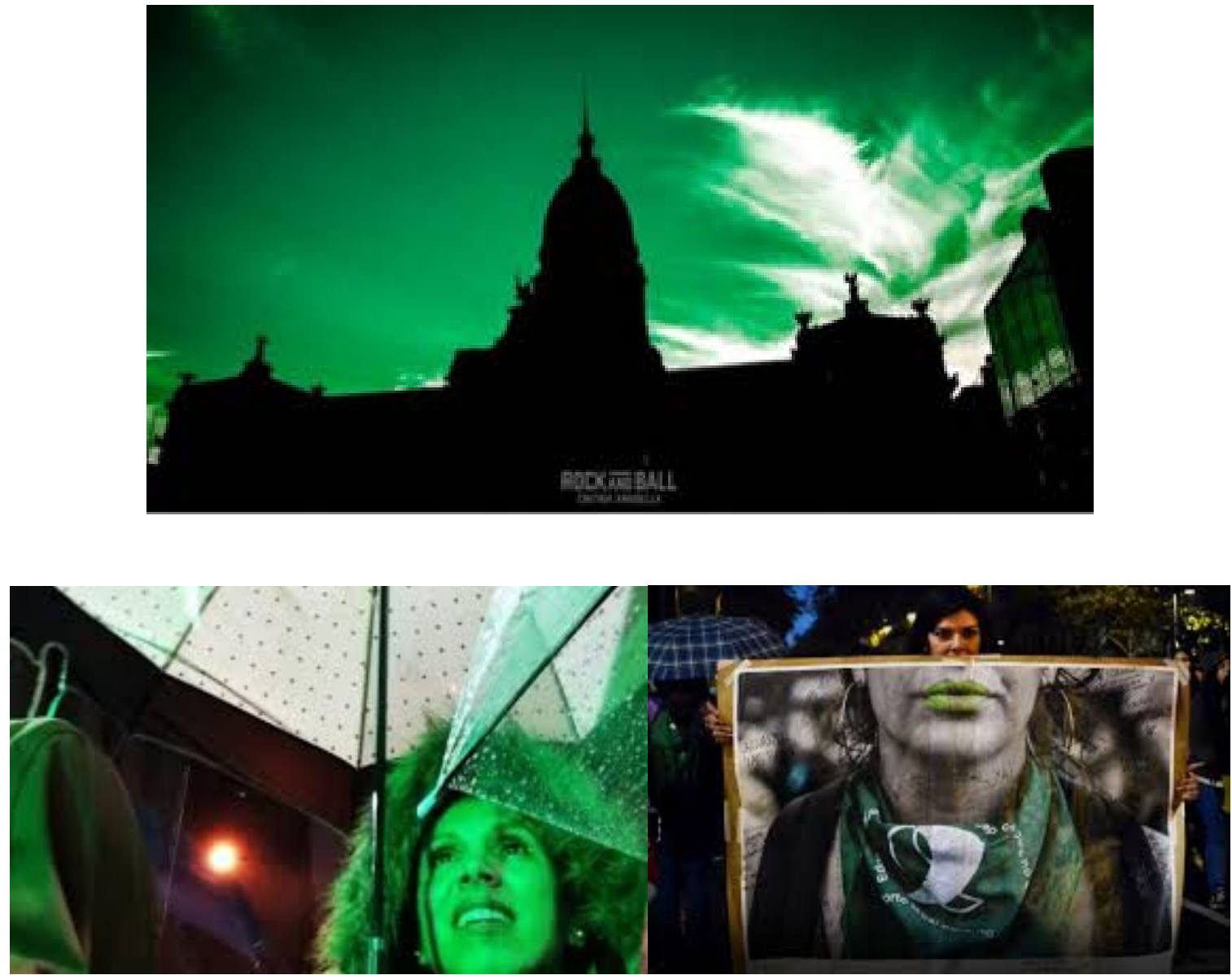

Fotogalería, perfil.com²

2https://www.perfil.com/noticias/politica/todas-las-fotos-de-la-historica-sesion-sobre-el-aborto.phtml 


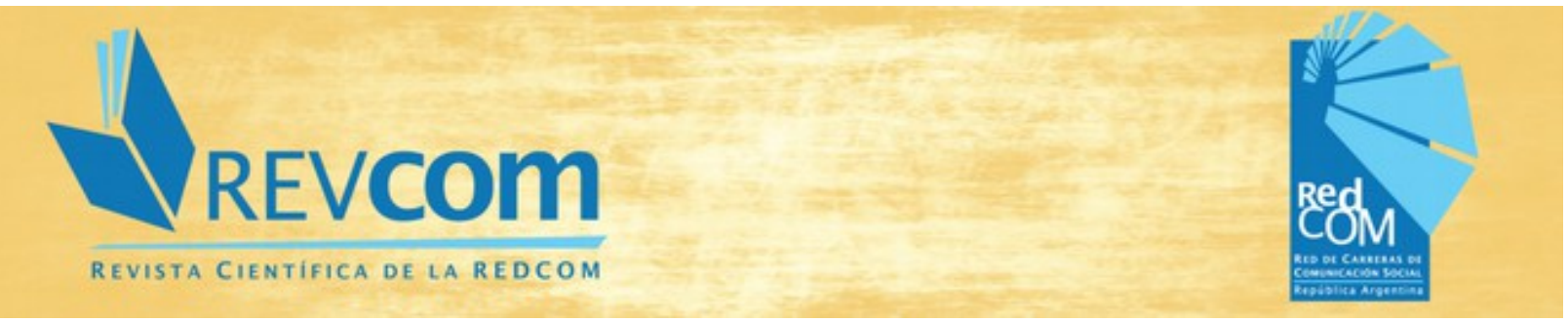

REVCOM | ISSN 2451-7836 | Año 4, \#8 | mayo de 2019 | Encuentros | e005

Entonces, vamos a ver, no hay ningún cielo verde, pero son efectos del photoshop, la cara verde también; pero, en algunos casos, el photoshop no existe, simplemente lo que toman es lo que las mismas militantes habían sobreinscripto sobre su propio cuerpo, es decir, habían semantizado su propio cuerpo, utilizando lápiz labial verde, carteles, pancartas.

Lo que vamos a ver es que hay una recurrencia, no sólo de la multitud sino del color, que es llevado al paroxismo: va a estar en la cartelería, va a estar en los bombos, los bombos son de color verde, va a estar en las pancartas y va a estar, inclusive, en las pelucas que se usaron para la ocasión.

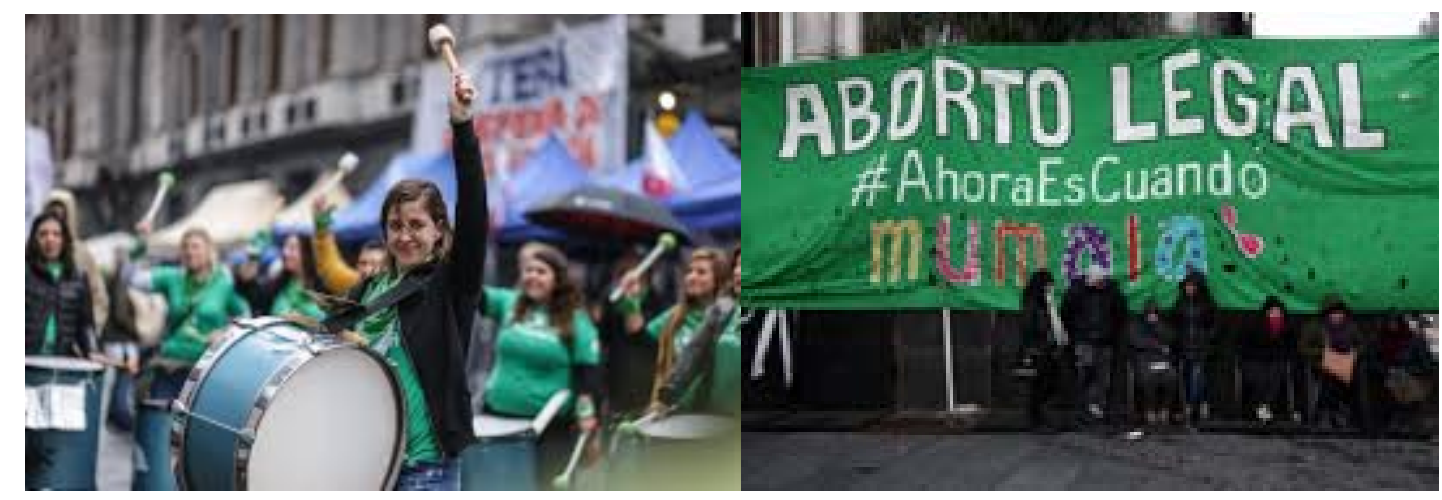

Fotogalería, clarin.com

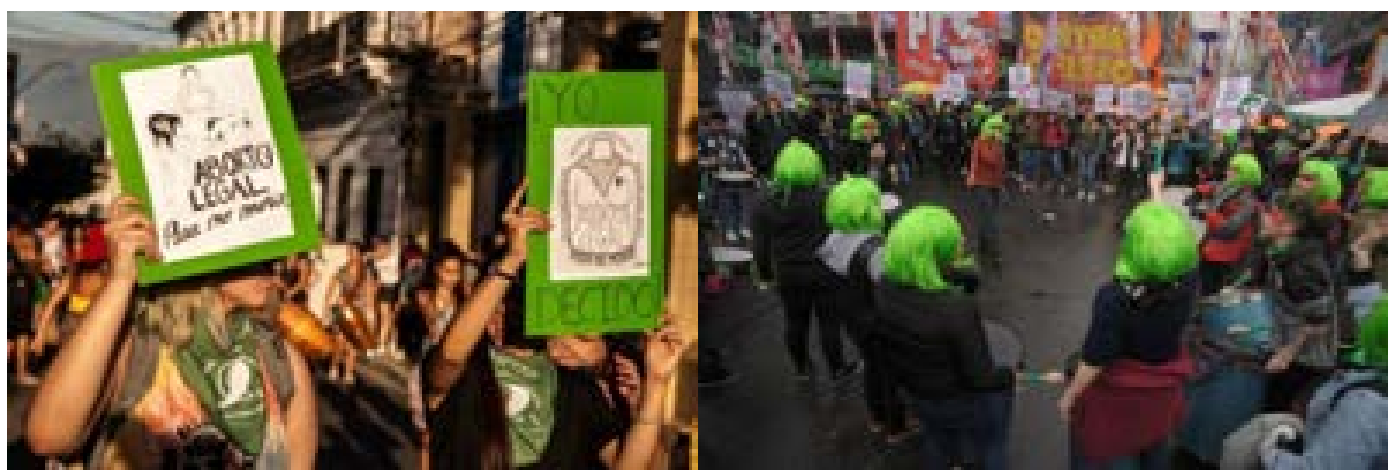

Fotogalerías de clarin,com y perfil.com

Y después, lo que es re interesante es el paso de víctimas a guerreras: la pintura, es la pintura de guerrera; no es el maquillaje con el que salimos a bailar, sino que es el maquillaje del guerrero; mujeres pintándose frente al espejo, pero pintándose como guerreras, un gesto femenino resignificado. 


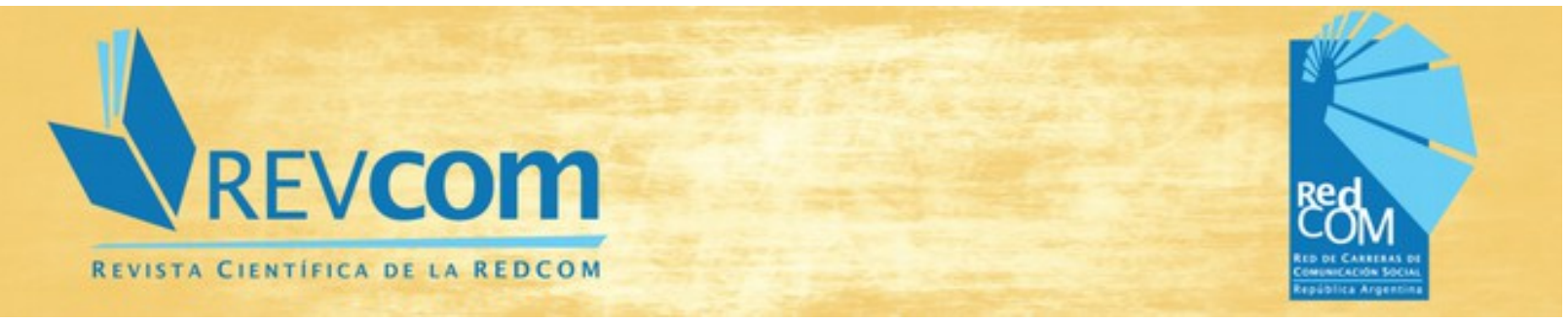

REVCOM | ISSN 2451-7836 | Año 4, \#8 | mayo de 2019 | Encuentros | e005

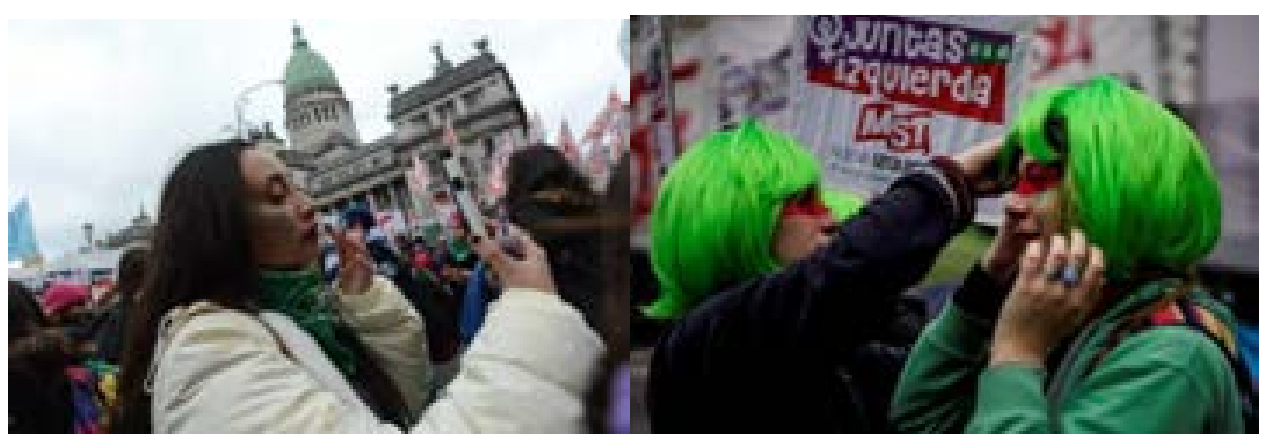

Fotogalerías de clarin.com y perfil.com

Lo dicho, pero no presente, estaba en el cuerpo vulnerado de las mujeres que morían, o que mueren, en abortos clandestinos, que es una forma de femicidio estatal por ausencia de leyes, pero además, porque el Estado está condenando a mayor cantidad de gente a la pobreza y estas mujeres se ven obligadas, cuando no quieren un embarazo a recurrir a abortos clandestinos con el resultado que ya todos conocemos. Esto estuvo presente en la cartelería, por ejemplo, en Página 12 hay una foto que dice el número de mujeres que han muerto por abortos clandestinos, la denuncia de que la pobreza es violencia estuvo presente y, también, carteles donde las chicas, sobre todo las jóvenes, están denunciando que no quieren ser obligadas a maternar.

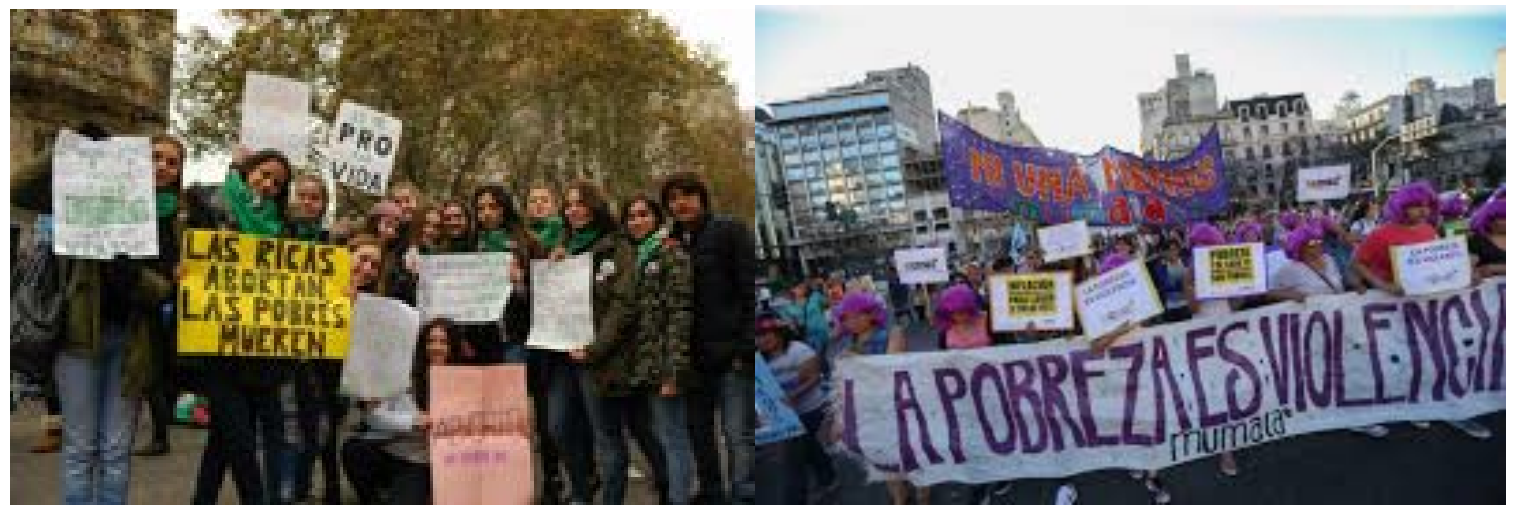

página 12.com ${ }^{3}$

3 Se trabajó con las versiones del diario on line publicadas durante el tiempo que duró el debate en los dos Congresos. 


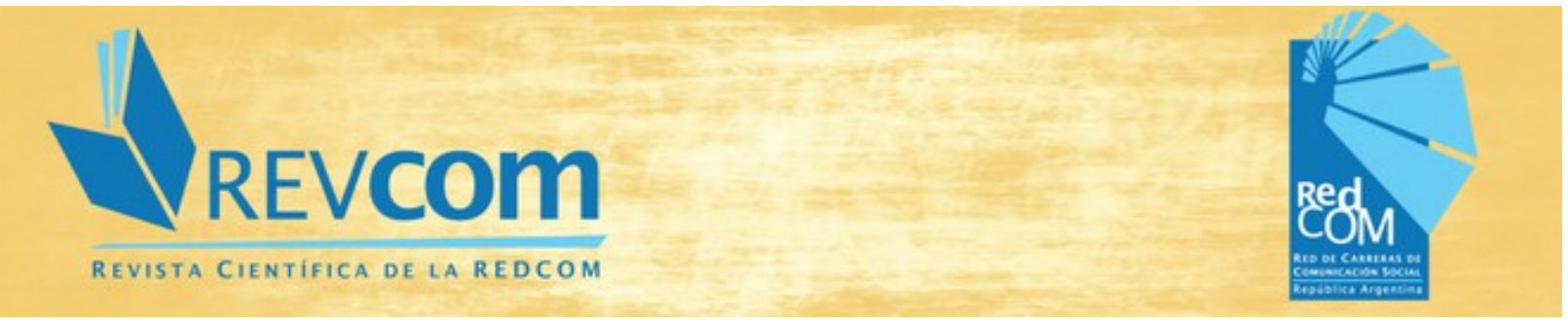

REVCOM | ISSN 2451-7836 | Año 4, \#8 | mayo de 2019 | Encuentros | e005

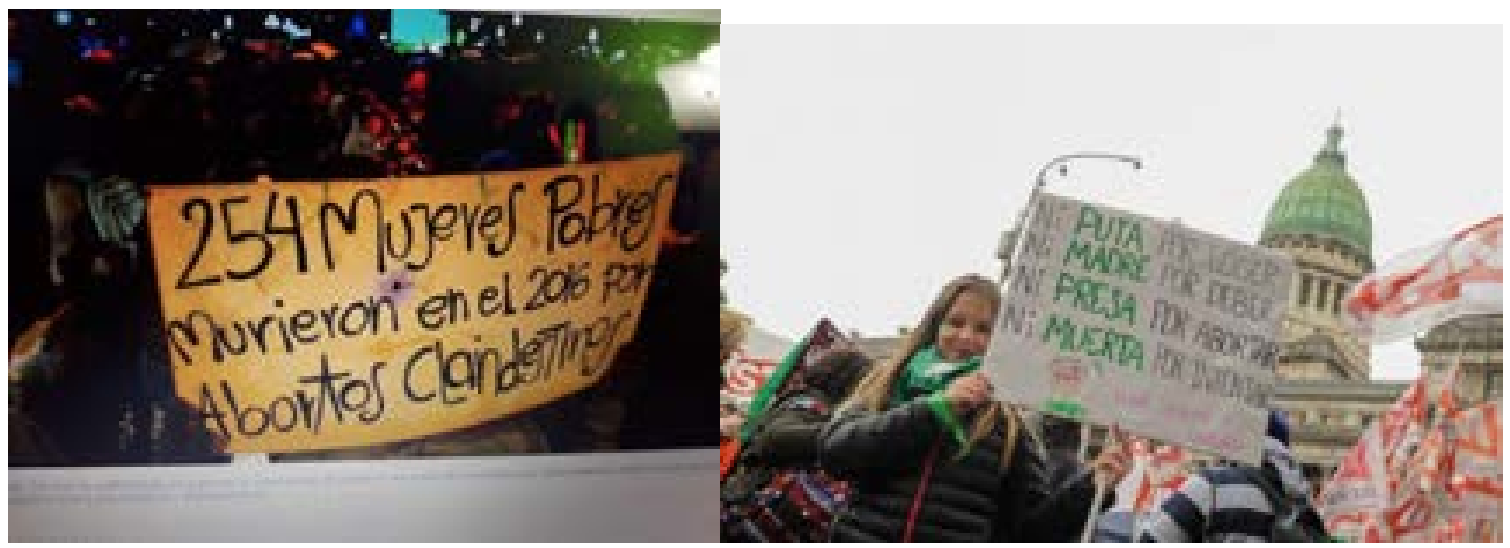

página 12.com y clarín.com

El cuerpo femenino está ausente. Es una ausencia espectral. En una foto que está tomada de una perfomance un cartel dice "Pobre porque desde la tumba no se puede hablar".

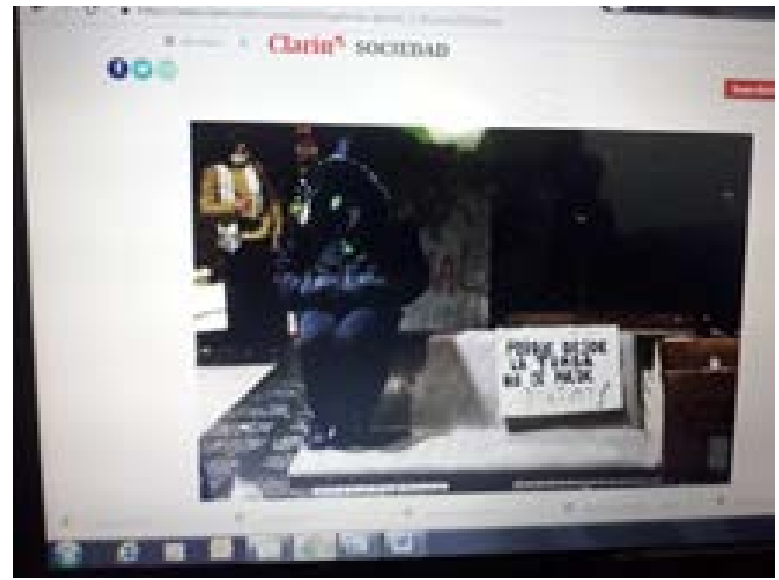

Fotogalería, clarin.com

Entonces se trata de una sustitución de un cuerpo que está negado y es sustituido por otro cuerpo femenino para defenderlo, representarlo, es decir, para volver a presentarlo, hacerlo visible, pero también audible en el espacio público, pero, el primero nunca va a perder su carácter de espectralidad.

Los medios van a ir pasando durante la cobertura en Diputados de una atenuación, en el caso de los medios como Clarín que son fuertemente patriarcales, o La Nación, a una imposible neutralidad que se ve por ejemplo en Perfil o en Infobae. Sumando el mismo número de fotos con valores eufóricos y con valores disfóricos a las mujeres, o pasando a la 


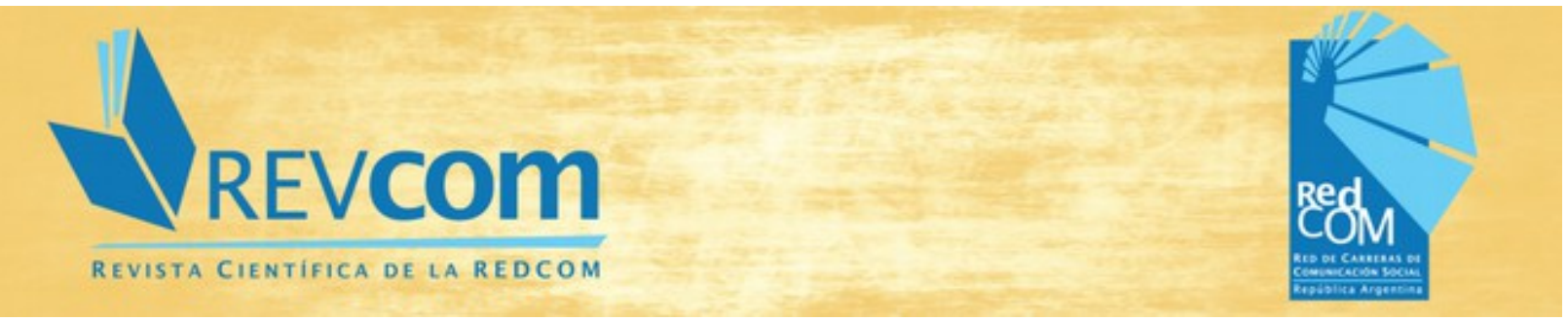

REVCOM | ISSN 2451-7836 | Año 4, \#8 | mayo de 2019 | Encuentros | e005

despolitización por el uso de una retórica que intenta hacer uso de la retórica de la objetividad. O sea, es un abanico de posibilidades que depende de los medios que se va a ir perdiendo a medida que se va a ir acercando el debate en Senadores.

Esto está relacionado con las condiciones de producción. Sabemos todos que los medios concentrados están al servicio del Gobierno, por lo tanto, también el Gobierno estaba expectante respecto al resultado porque la grieta los estaba atravesando a ellos también, adentro del partido y de las bancadas. Entonces, no sabían qué iba a pasar ni cómo iba a terminar la sociedad reaccionando frente a un resultado o a otro. Entonces, lo que sí empieza a aparecer porque nunca dejan las líneas editoriales los diarios, son formas de estigmatización, sobre todo de la demonización; habitualmente una de las estrategias más utilizadas para representar a las mujeres es demonizarlas, o representarlas como un marimacho violento, o criminalizarlas.
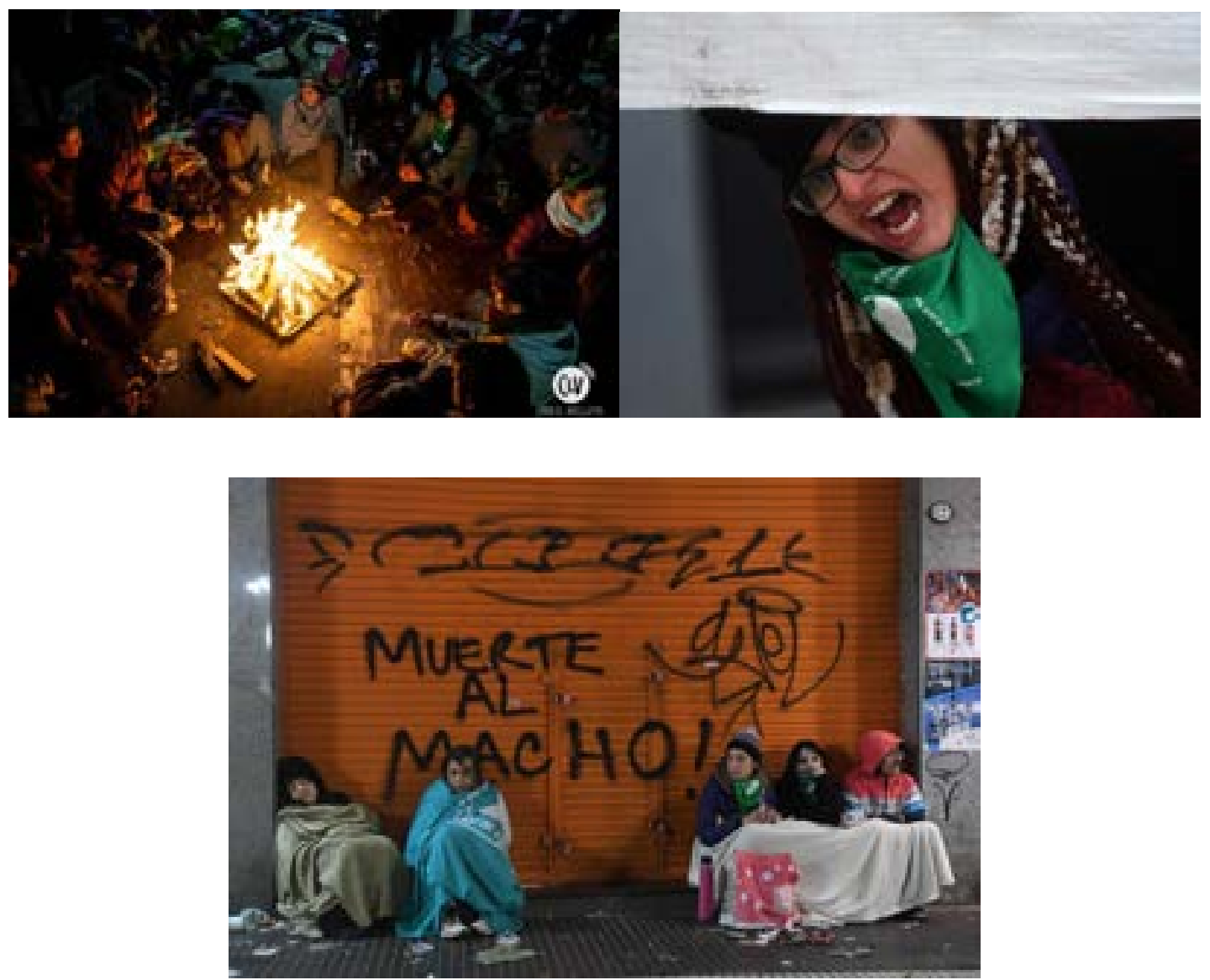

Fotogalería, clarin.com 


\section{$\forall$ REVCom \\ REVISTA CIENTIFICA DE LA REDCOM}

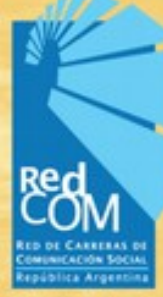

REVCOM | ISSN 2451-7836 | Año 4, \#8 | mayo de 2019 | Encuentros | e005

Por ejemplo, con el uso del fuego, la memoria de las marchas anteriores, las expresiones faciales y corporales al momento de fotografiarlas, o con las pintadas, esto en la época de la atenuación; la atenuación se construye con la presencia de la metonimia y de la sinécdoque, que son dos figuras retóricas que tienen que ver con la contigüidad semántica.

En contraste, la búsqueda de la neutralidad los llevaba a poner el foco en valores más positivos, más eufóricos, por ejemplo la sororidad representada en la celebración del día 15, ¿por qué? Lo que se intenta es quebrar el estigma que, en este caso, no era dicho por los medios sino por las asociaciones autodenominadas "Pro-vida", que nos llamaron "asesinas de bebés", "machonas", "feminazis", "víbora del monte chaqueño"; y por otro lado, buscaban lo artístico y lo estético, pasando de la ironía responsiva, como una forma de proponer un intervalo, a la marea verde sin dejar de decir lo mismo pero, al mismo tiempo, de proponer nuevos lenguajes a la multitud feminista.

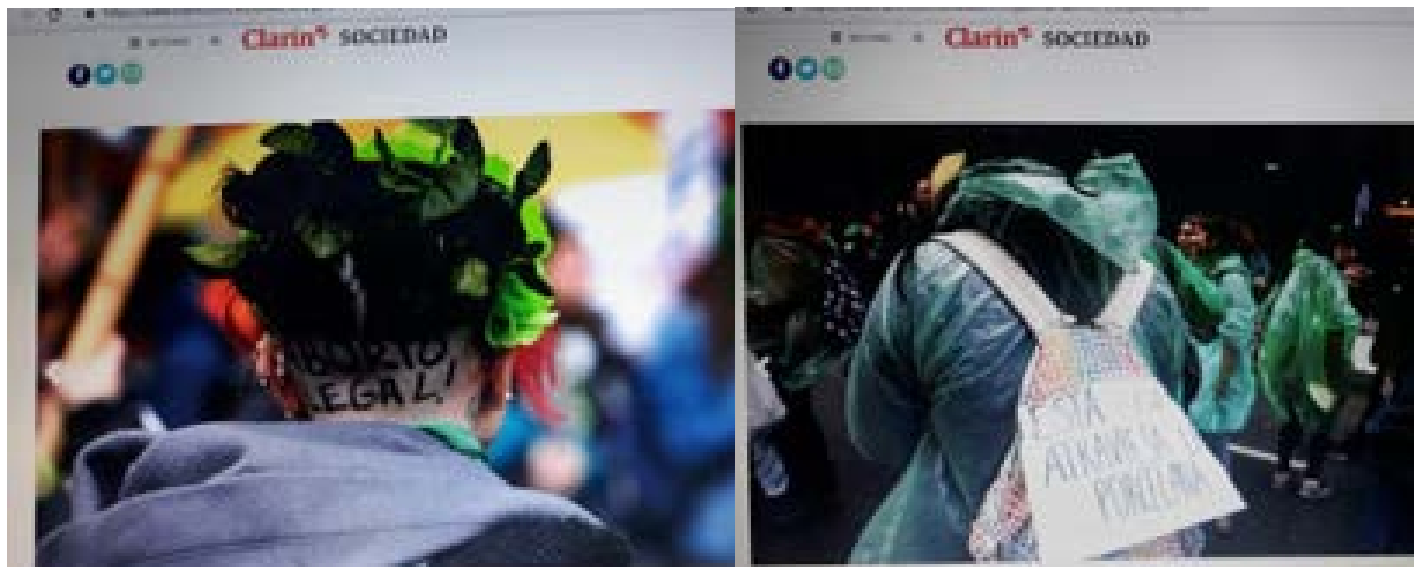

Fotogalería, clarin.com

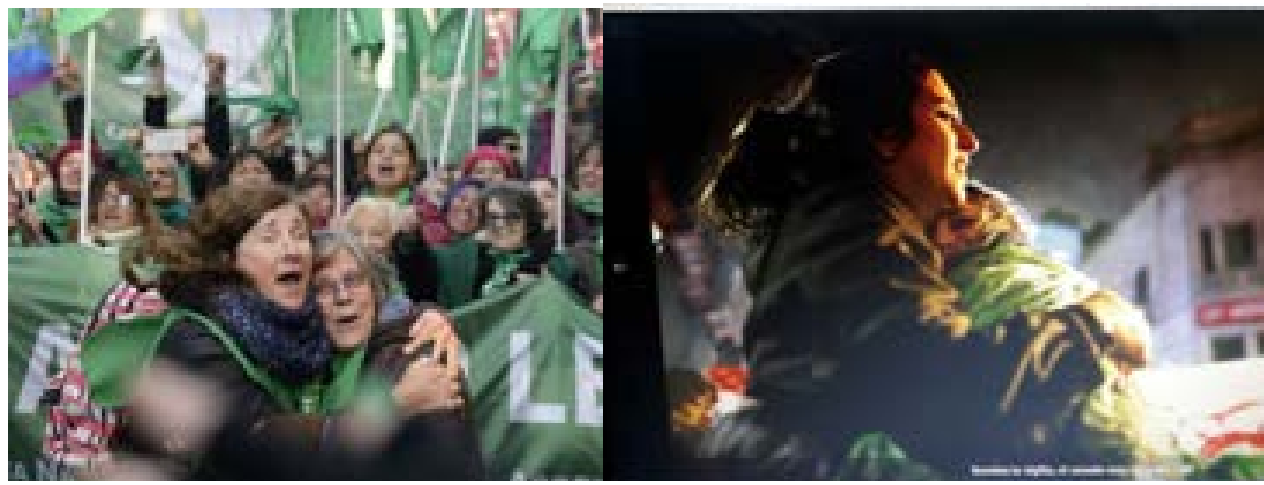

pagina12.com 


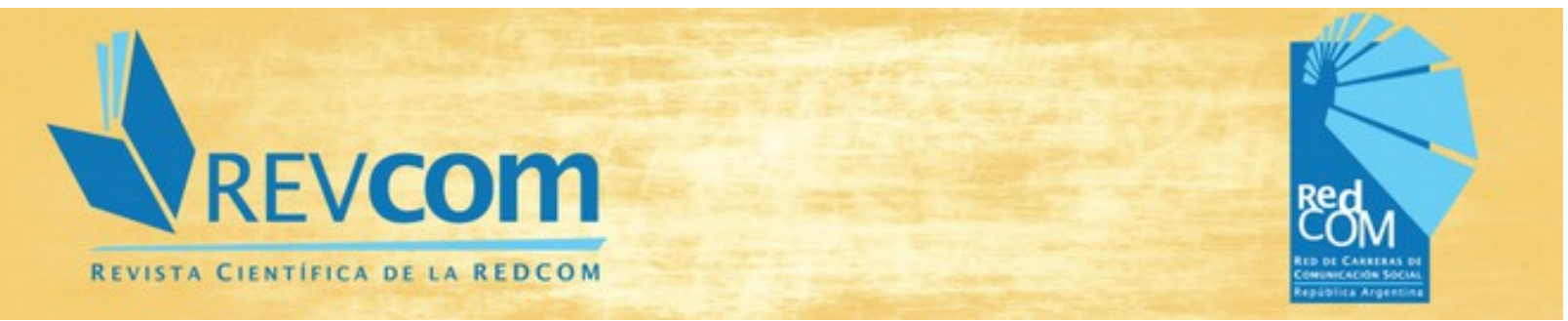

REVCOM | ISSN 2451-7836 | Año 4, \#8 | mayo de 2019 | Encuentros | e005

Además, hay una cosa muy interesante en las marchas de mujeres que es la alegría, y la alegría, en este caso, tiene que ver con el carnaval bajtiniano, con la risa que sale desde adentro, y que siempre es una risa liberadora, y en las fotos se ven ambas cuestiones.

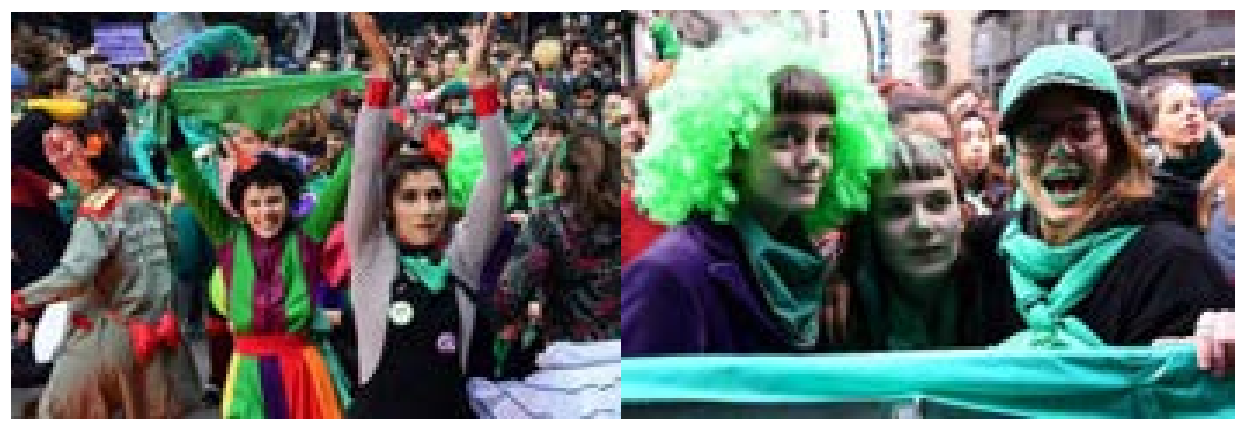

Fotogalería, clarin.com

A medida que vamos al Senado, esta aparente imparcialidad mediática se va a focalizar primero en lo que la misma prensa va a llamar "la grieta" y después va a construir la antítesis como matriz de sentido. Pañuelos verdes versus celestes, la grieta del Gobierno por el aborto legal. La figura de la antítesis que da cuenta de la oposición irreconciliable pero en paridad de dos términos.

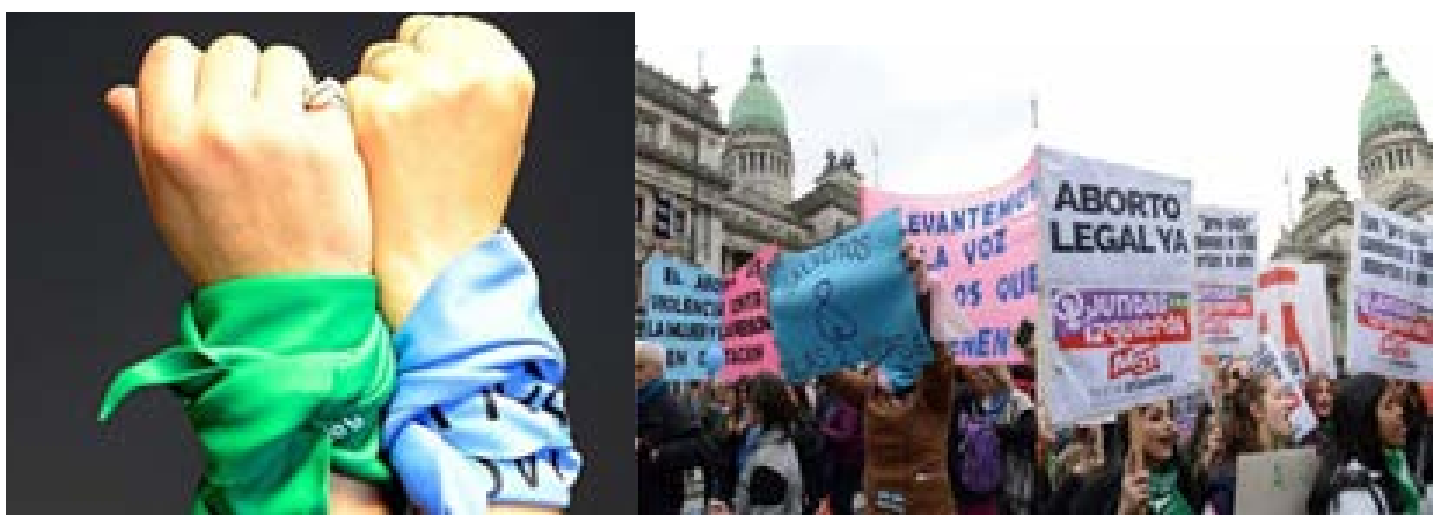

Fotogalerías, perfil.com y clarin.com 
REVCOM | ISSN 2451-7836 | Año 4, \#8 | mayo de 2019 | Encuentros | e005

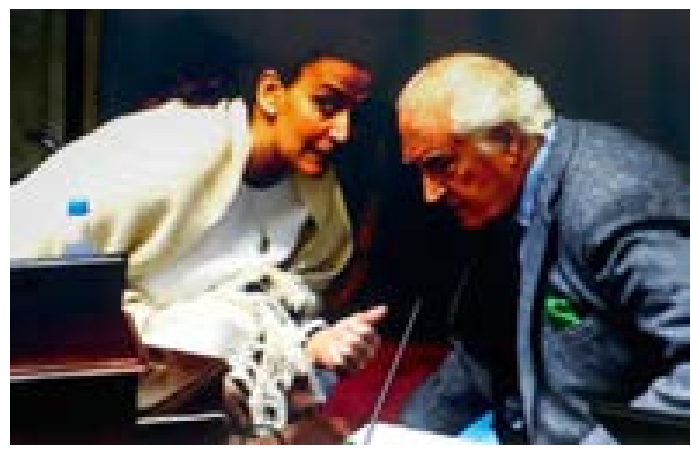

En el fotoperiodismo es donde mejor se ve; de la misma forma que en el caso de la semantización, lo vamos a ver o por plano detalle o por construcción en la política del encuadre o por edición: la foto que equipara celestes y verdes con el Congreso espejado, por ejemplo.

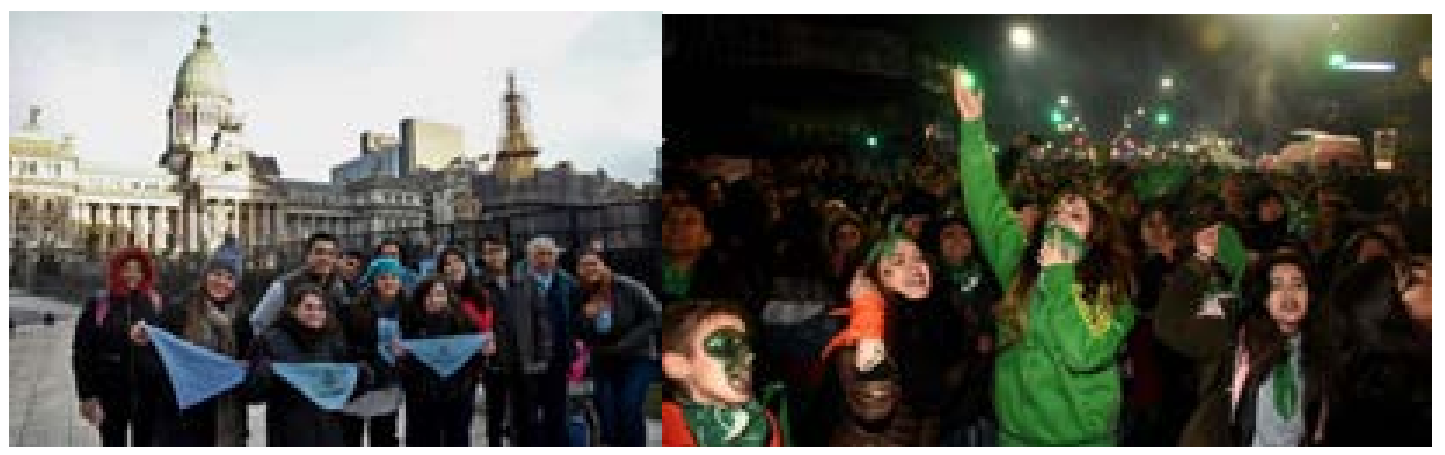

Fotogalerías, clarin.com e infobae.com

Entonces, la matriz antitética se va a leer en todas las fotografías de los llamados 'Provida", porque el discurso "Pro-vida" se construye sobre el discurso de las verdes.

Esto está dando cuenta, para mí, de que la antítesis, la grieta, había hecho que dentro y fuera del recinto la discusión se transfomara en esa categoría de Marc Angenot que es el "diálogo de sordos", es decir, nadie escucha a nadie porque hay en este caso una CERRAZÓN O SIN RAZÓN ideológica, es imposible escuchar al otro, no importa lo que diga, no interesa, ya no hay escucha, no hay audibilidad posible, por lo tanto es imposible la comunicación, menos el acuerdo o el consenso.

Se contrastan en la construcción de las imágenes las marchas Pro-ley y "Pro-vida": mujeres vs hombres llevando pancartas, cuerpos pintados vs. caras lavadas, expresiones 


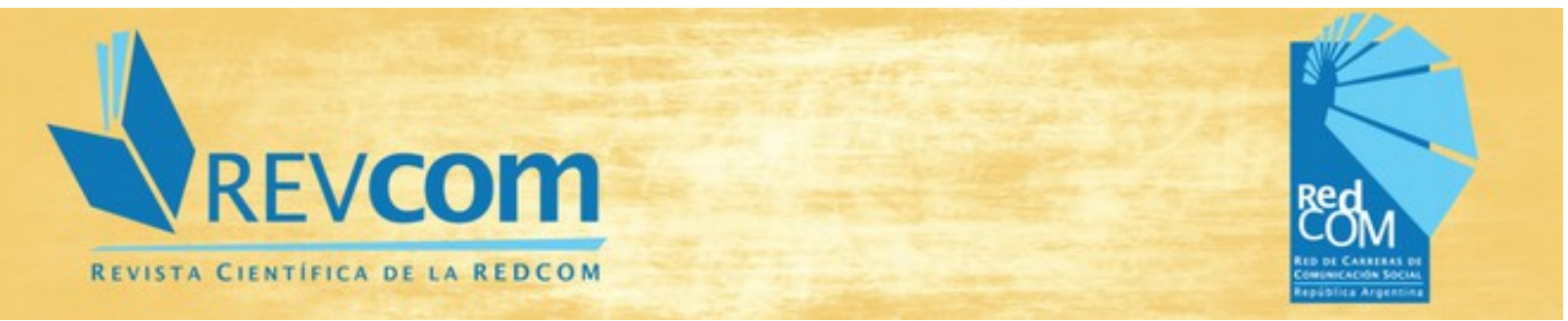

REVCOM | ISSN 2451-7836 | Año 4, \#8 | mayo de 2019 | Encuentros | e005

guerreras vs. actitudes calmas. Y también se ve la misma estrategia de semantización pero, esta vez, hecha con globos y con el color celeste.

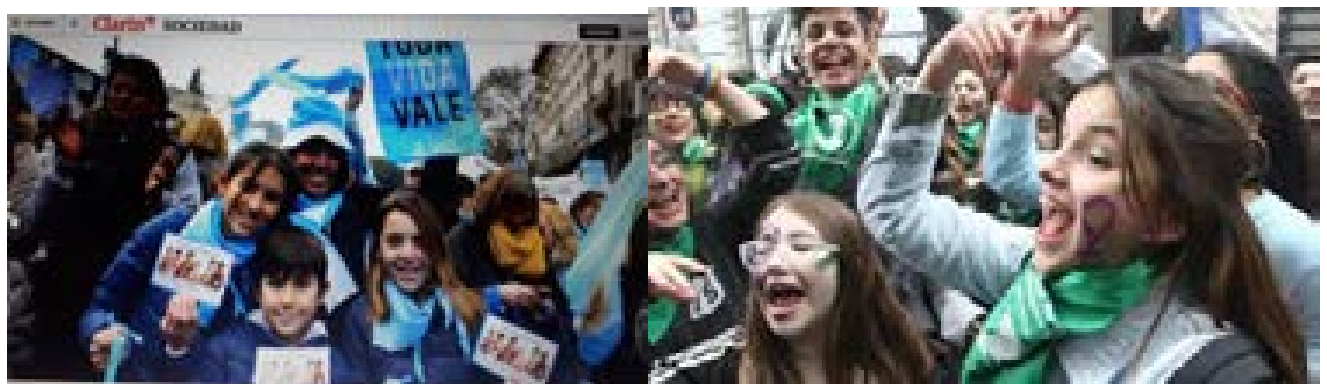

Fotogalería, clarin.com

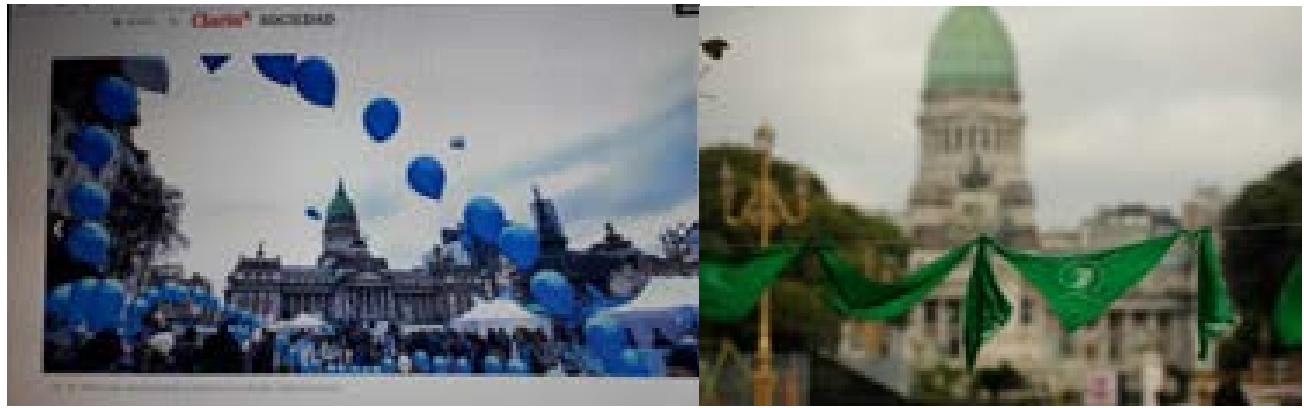

Fotogalería, clarin.com

El icono que se eligió y que se usó recurrentemente hasta el paroxismo fue el del feto, se vio en llaveros, en souvenires, en estatuas gigantes, que dan cuenta de la figura del hipérbaton, de la exageración; lo que se exagera es una humanidad imposible, es decir, que implica una metonimia, la relación de contigüidad feto va a ser bebé, causa-consecuencia, pero bebé nacido; esto le da un indudable estatuto humano con derechos, que se va a transformar en identidad: el feto es un ser humano como ustedes, como yo, que tiene los mismos derechos de ciudadanía, por lo tanto, es un argumento contra el aborto. Todo esto entre comillas. 


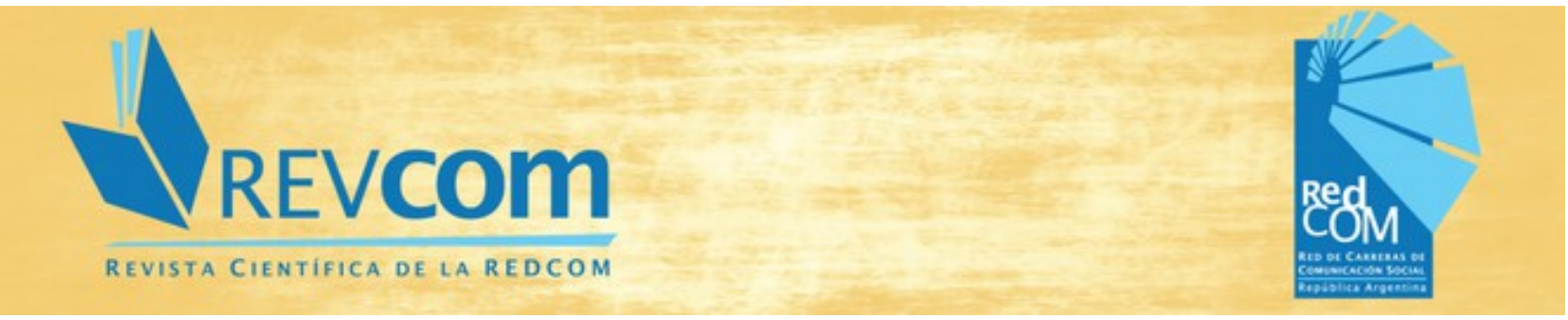

REVCOM | ISSN 2451-7836 | Año 4, \#8 | mayo de 2019 | Encuentros | e005

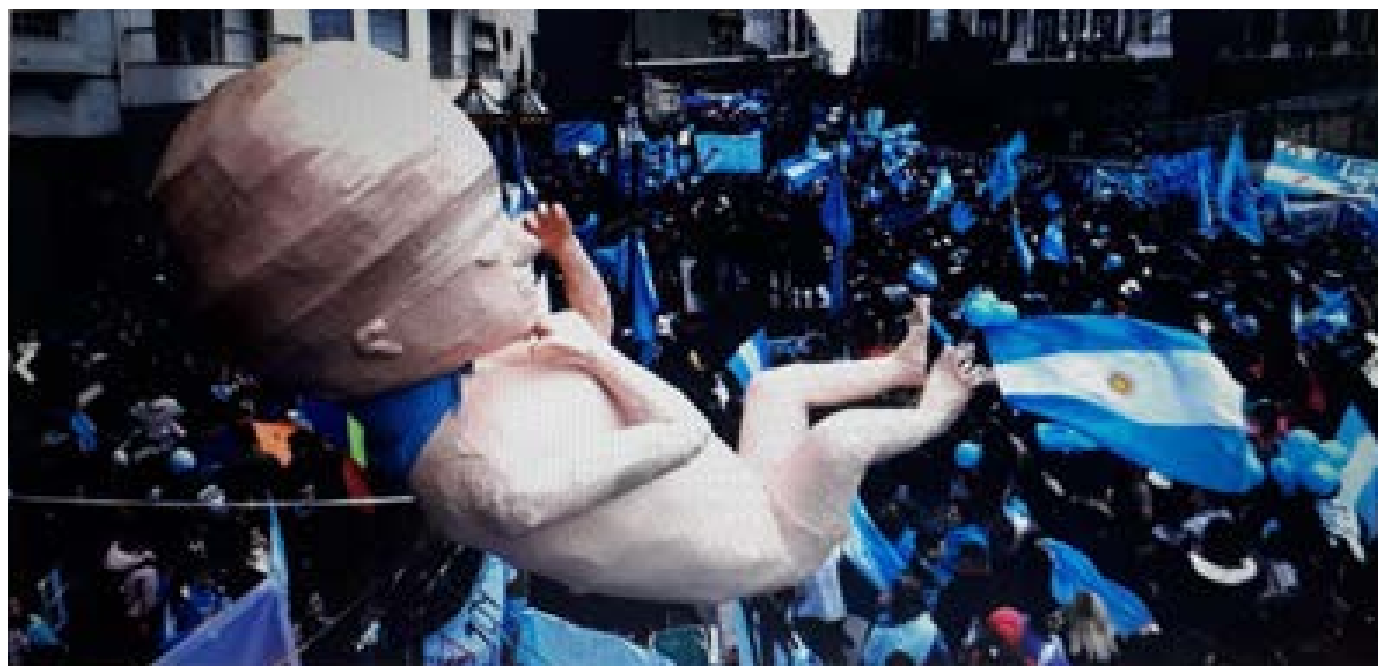

Fotogalería, clarin.com

Lo que se ve también en la cartelería es el uso de la mentira, el argumento falaz ya rozaba la mentira, por ejemplo: "Legal o ilegal, mata igual", ¿a quién mata igual? No mata igual a las mujeres, o sea, ahí hay algo que no se está diciendo, entre otros casos de, por ejemplo, verdades irrefutables por la fe, por el canon, entonces es casi imposible la discusión.

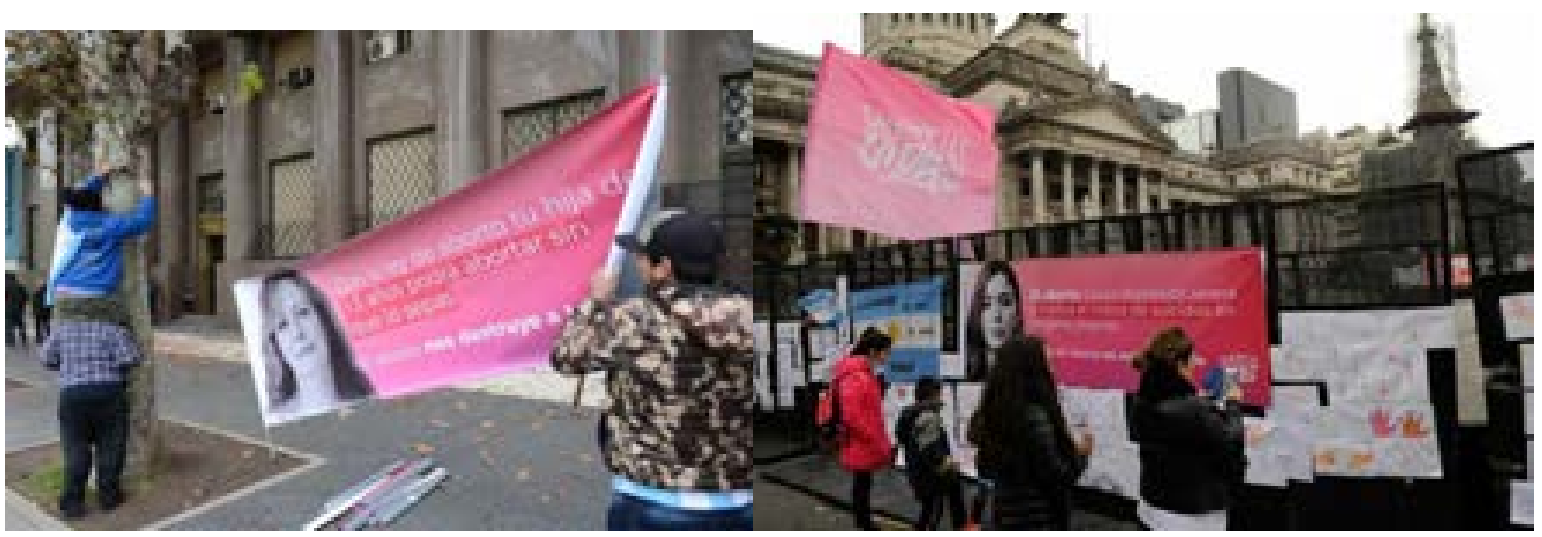

Fotogalería, clarín.com

La otra novedad en la calle es la fuerza impronta del discurso católico y de la presencia de religiosos católicos y católicas. Entonces, aquí los medios van a construir una iconografía donde ponen de relieve banderas, cruces, rosarios, Biblias, Niño Dios que evoca en lo no dicho al famoso feto. Entonces, de alguna forma, los medios al registrar transforman una marcha no en algo de protesta, no en algo que corta las calles y es molesto (que son molestas las procesiones para los no católicos), sino en una procesión. 


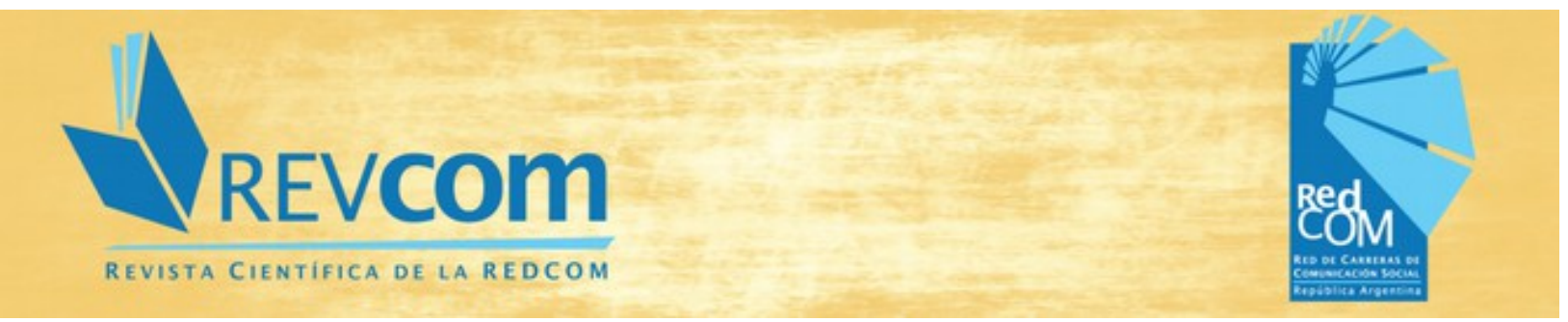

REVCOM | ISSN 2451-7836 | Año 4, \#8 | mayo de 2019 | Encuentros | e005

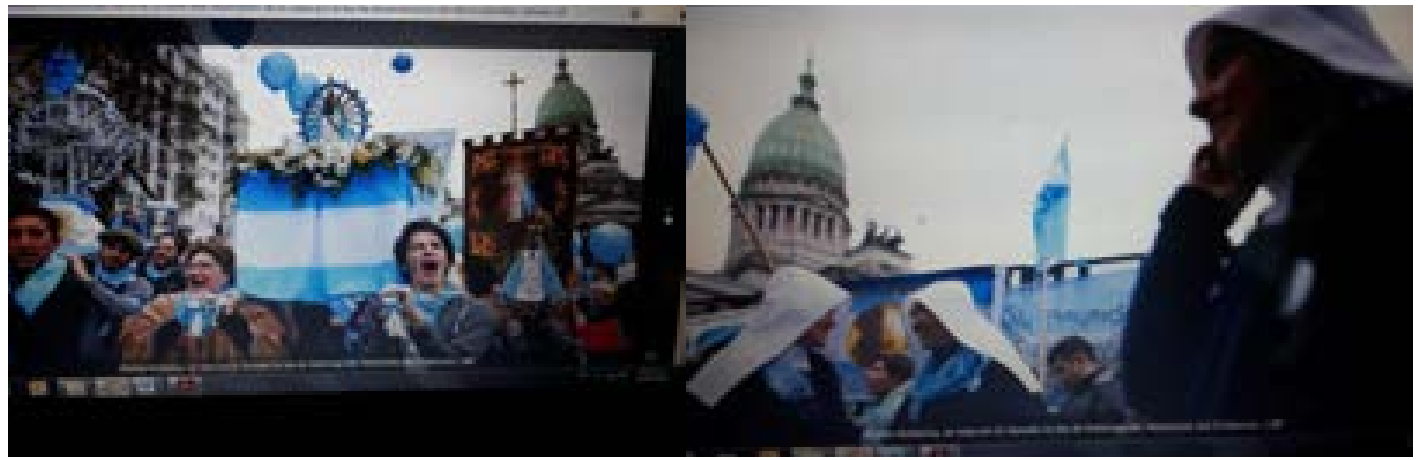

Fotogalería, clarín.com`

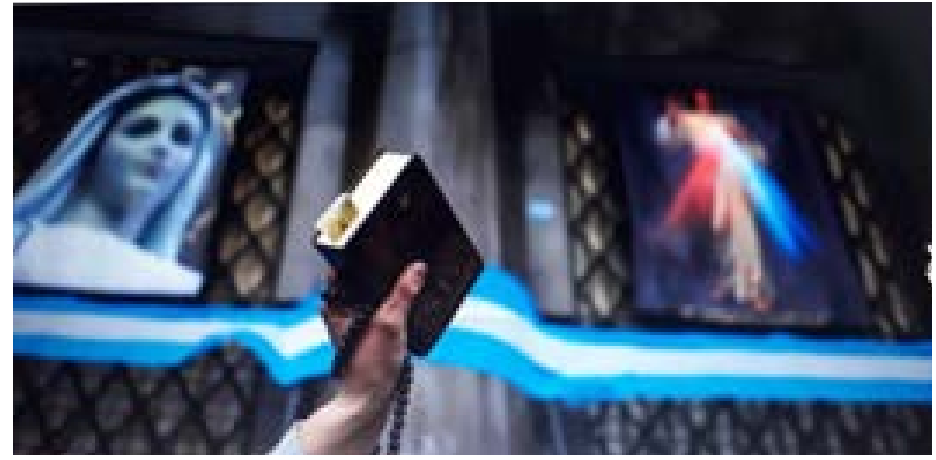

Fotogalería, clarín.com

Así, reúne iconografía que remite a la religión católica y a la bandera argentina porque llegamos a la apropiación de los emblemas identitarios. El color celeste no sale del aire, sale de nuestra bandera; ¿por qué? porque nuestra bandera está legitimada, pero además porque produce fuerte efecto de identificación y lo vemos también con las banderas provinciales.

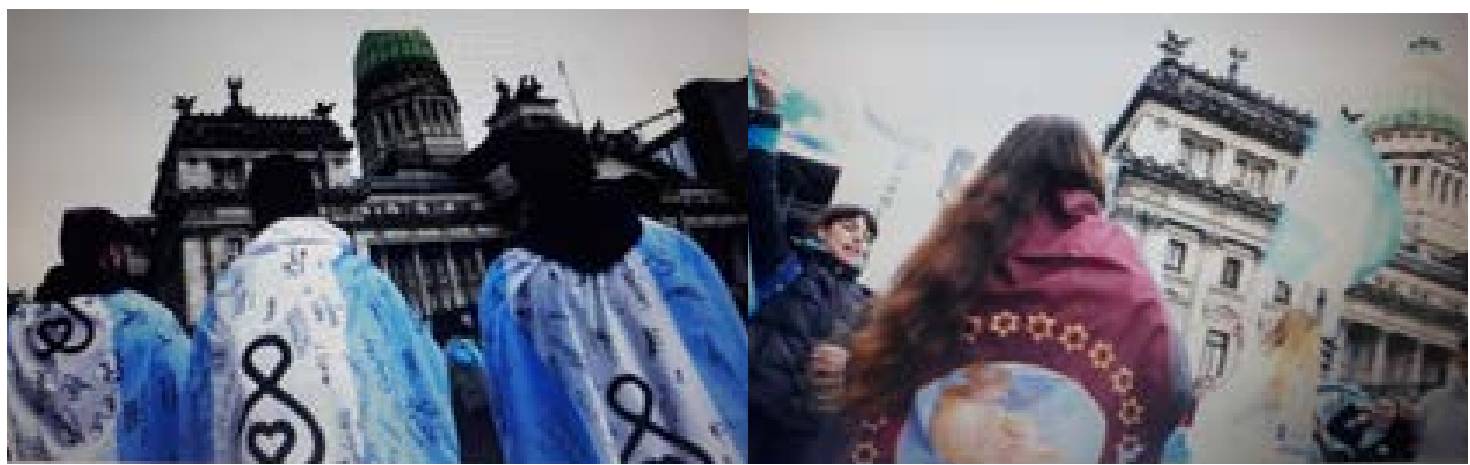

Fotogalería, clarín.com

¿Por qué es tan eficaz la estrategia de apropiación y por qué se utiliza? Primero, porque copia una estrategia que ha sido eficiente para la contaminación que ha sido la de los pañuelos 
REVCOM | ISSN 2451-7836 | Año 4, \#8 | mayo de 2019 | Encuentros | e005

cambiados de color; hay una apropiación también semántica: al autodenominarse "Pro-vida" se le da mayor legitimidad al reclamo pero se oculta que las mujeres que luchamos por la IVE estamos por la vida, no por la muerte y nos atribuyen a nosotras la calificación de asesinas de bebés, con lo cual se está negando todo argumento científico que es reemplazado por lo que dice el dogma, la desigualdad social que está a la base de las muertes por estos abortos sépticos Es algo terrible porque ellos decían: "Ahora sí queremos que implementen la ESI" , y ahora ¿qué está pasando? que no quieren que implementen la ESI. Por eso les digo que a la base hay también una cuestión de mentir directa y llanamente.

¿Cuál es la evaluación mediática? A medida que se iban contando los votos y se veía que iba a ganar el No, la evaluación negativa, sobre todo de los medios que históricamente viven criticando, criminalizando y demonizando a las mujeres, va a hacerse más y más evidente; por otro lado, los valores eufóricos van a correrse de la marea verde a la marea celeste y se va a hacer mucho hincapié en el tema de los colores patrios porque ¿quién ve la bandera como algo negativo?, nadie. Surgen entonces las fotos eufóricas, lindas y agradables.

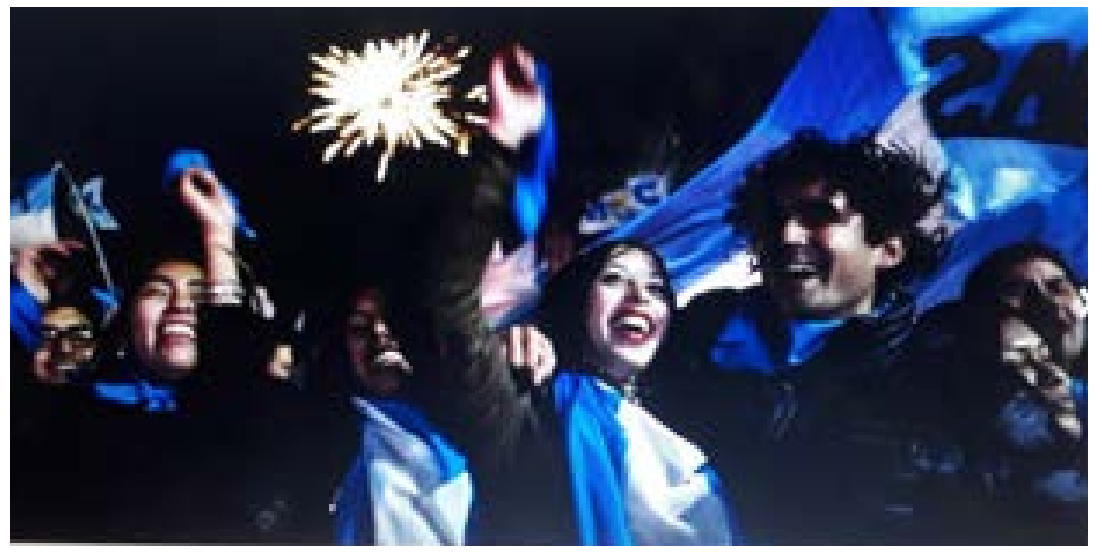

Fotogalería, clarin.com

Unos incidentes frente al Senado fueron la ocasión perfecta para traer toda la demonización, la identificación de los manifestantes con delincuentes e inclusive con terroristas, a I hacer hincapié en el humo (que en realidad es el efecto de los gases lacrimógenos). 
REVCOM | ISSN 2451-7836 | Año 4, \#8 | mayo de 2019 | Encuentros | e005

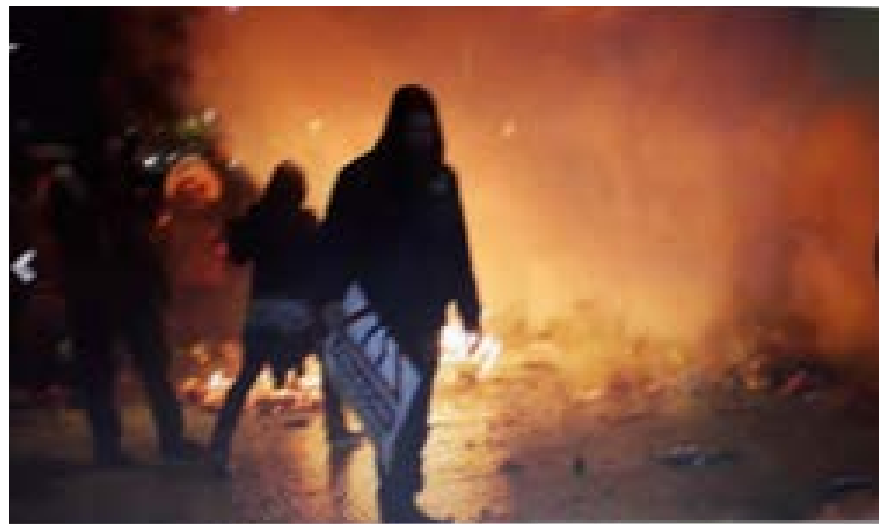

Fotogalería, clarín.com

Pero la foto da cuenta de otra cosa además, una militante con el pañuelo verde arrastrada por la policía, se justifica la represión lo que es injustificable, pero a la vez se criminaliza a través de un primer plano en la cara y en el pañuelo, no en la policía, ni en los golpes, ni en la represión; y empiezan a ser más recurrentes las caras tapadas de las manifestantes, que era una opción, también en reacción, la resistencia es ponerse en el lugar donde te pone el poder y desde ahí hacerlo estallar pero, en este caso, ya en este otro contexto de criminalización y demonización, pasan a ser como si fueran terroristas, queda esa idea instalada.

Se construye entonces un campo semántico donde lo bueno es la Iglesia, sus valores, el orden represivo, lo masculino, que se opone a lo malo que sería lo pecaminoso, la militancia de género, la criminalidad, el feminismo, lo femenino. La entonación negativa se sostiene en un paquete de herramientas que operan al nivel del relato visual.

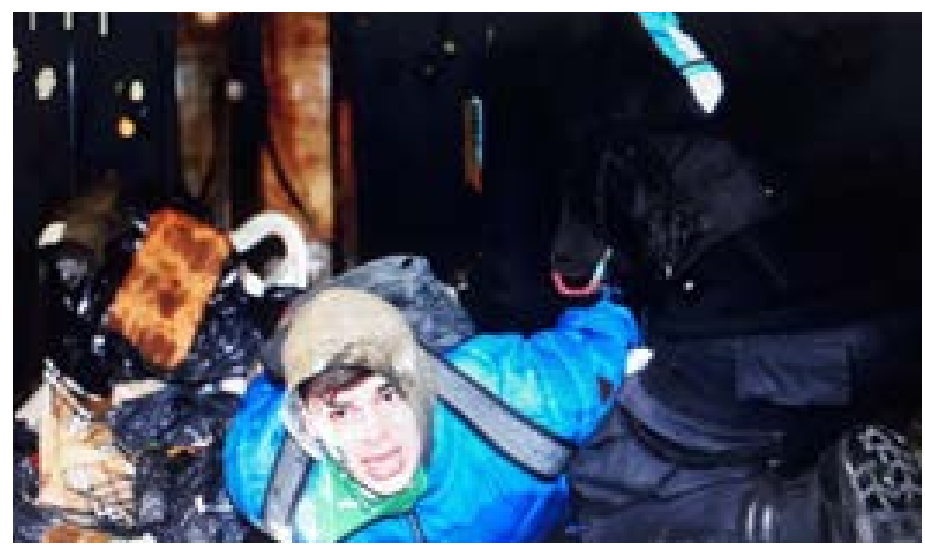

Fotogalería, clarin.com 
REVCOM | ISSN 2451-7836 | Año 4, \#8 | mayo de 2019 | Encuentros | e005

Si yo en vez de tomar la marcha desde arriba, hago un travelling y voy a focalizar y recortar en un suceso violento hago dos recortes semánticos: por un lado, niego la multitud, hay cuatro y son todos violentos, pero como yo ya vi la multitud le voy a atribuir eso a los otros y, por otro lado, voy a naturalizar la perspectiva ideológica con la que siempre se cubrieron estas marchas desde estos lugares.

Cuando las mujeres nos organizamos, la tierra tiembla, aseguraron las dirigentes de las organizaciones de género el año pasado durante el 8M Paro Internacional de Mujeres, y los temblores abren grietas por las que se cuelan representaciones y valores con perspectiva de género a través de una cobertura ambigua de estas marchas, efecto performativo de la doble enunciación de los cuerpos femeninos puestos en el espacio público con escrituras liberadoras opuestas a la brutal escritura machista, de los cuerpos muertos en abortos clandestinos, prácticas obligadas por leyes patriarcales a las que justamente este tipo de manifestaciones pretendían poner un necesario final.

Por la grieta, también se cuelan los debates, las contradicciones, que son dichas por las antítesis, la reacción patriarcal, heterosexuada, católica y también colonial. Entonces, hemos visto, cómo la cobertura y el encuadre de estas marchas depende de muchos factores: primero, la multitudinaria convocatoria que realiza un corte abrupto en la vida cotidiana y obliga a los medios a cambiar sus agendas de trabajo y a las audiencias a destinar tiempo a consumirlo para poder ser testigo de un evento que no solo se percibió como histórico sino que lo fue; la importancia del suceso va a obligar a los medios a cubrirlo, a informar sobre el mismo desde un lugar ideológico no tan explícitamente negativo, porque va a resultar de la negociación entre el impacto de la masividad que tuvo en la sociedad y en sus consumidores y la línea editorial del medio; más allá de los intentos de esos mismos medios por mostrar esta marcha de una forma o de otra, siempre el resultado es dual y contradictorio por el funcionamiento de la antítesis y el oxímoron a la base de toda la producción de sentido de estos discursos. Además, porque lo que comienza siendo una retórica de las feministas al asumirse como sujetos de enunciación y como agentes de transformación que reclaman derechos y propia dignidad es asumida y apropiada por el patriarcado, y este gesto tiene consecuencias que van más allá de lo discursivo y nuevamente se transforman en un acto de enunciación doble: siempre la palabra 
REVCOM | ISSN 2451-7836 | Año 4, \#8 | mayo de 2019 | Encuentros | e005

dicha, escrita, inscrita y cantada y con el cuerpo ocupando y desplazándose en el espacio público más la reduplicación que hacen en forma visual y por el discurso verbal los medios.

Para Julia Kristeva la enunciación es una articulación del lenguaje en curso que supone el intento de captar el presente en su paso hacia el futuro y como tal está íntimamente ligada al reconocimiento que en el ámbito de las minorías. Es un reclamo a la autoridad por parte de un grupo emergente que busca reafirmar su identidad colectiva. En este caso, la aspiración se asocia al reclamo \#SeráLey cargado de futuridad y si no me creen, esto es lo último que está circulando en las redes: \#SeguimosAcá, proceso de semantización, \#SomosUnMontón. Esto todavía no ha concluido.

Muchas gracias.

Daniel Rosso: Voy a desarrollar algunos elementos recientes del discurso de Cambiemos tomando algunos ejemplos muy de coyuntura para poder ejemplificar.

Como ustedes saben hace unos días el Presidente hizo un spot que distribuyó en redes sociales en donde ingresaba a una pequeña pizzería en Ingeniero Maschwitz que es una ciudad cercana a la Capital Federal, una pizzería llamada II Calzone di la Nona, y ahí estaban trabajando sus dueños Verónica Krieguer y Federico Nicotra. Aparece en principio como una escena libre de política, es decir, Macri llega al lugar acompañado por su pequeña hija y Verónica, la emprendedora, luego de sorprenderse entre comillas por la visita presidencial, asegura "podemos demostrar que sí se puede, que sí hay un proyecto, que se puede salir adelante, pero que tenemos que colaborar entre todos". Esta idea manifestada por la pizzera pospolítica de algún modo es recurrente en el discurso reciente de Cambiemos, yo creo que en todo su discurso, que es su composición pospolítica. ¿Qué quiere decir eso? Como ustedes saben, la política requiere de la confrontación entre por lo menos dos discursos, por eso la democracia es el debate entre proyectos distintos. Pero Cambiemos apuesta a un más allá de la política, a ese lugar que Chantal Mouffe llama la pospolítica, es decir, el consenso de todas las partes, de todos los habitantes de un país alrededor de un proyecto único.

Entonces, en esta voz, en esta frase de los pizzeros de Ingeniero Maschwitz, y en otras que encontramos más o menos contemporáneas a esta, la democracia es el sistema donde reina un modelo de país único que todos y todas tenemos que apoyar. Es decir, en el hay diálogo sólo si este conduce al consenso, de allí que la pospolítica esconda siempre como un componente autoritario, porque los resultados de las discusiones están siempre antes de que 
REVCOM | ISSN 2451-7836 | Año 4, \#8 | mayo de 2019 | Encuentros | e005

estas se produzcan, los diálogos chocan todo el tiempo con puntos de vista gubernamentales que no se modifican. La convocatoria al debate es, en general, un llamado a acordar lo que el Ejecutivo y ahora además, los organismos multilaterales de crédito, previamente han decidido. Por eso, la promesa actual del Gobierno ante la crisis es que no va a cambiar, es decir, la identidad del oficialismo es un contrasentido, porque Cambiemos no cambia, o sea su mayor oferta discursiva que tiene de momento es que no cambia y, efectivamente, no cambia porque no puede cambiar; porque se lo hace imposible la matriz pospolítica en donde está ubicado, porque expresa un proyecto único supuestamente consensuado por todos los argentinos y las argentinas; es decir, la pospolítica no tiene exterior, es un territorio excluyente, luego de ella está el abismo, está el precipicio.

Entonces si este planteo en la pospolítica es un territorio único de un proyecto único al cuál todos tenemos que apoyar, ¿qué sucede con los que resisten a formar parte de ese consenso alrededor de ese modelo de país único? Bueno, ahí se activan dispositivos políticos, judiciales, mediáticos, para estigmatizar, segregar y, eventualmente, reprimir a eso que no se normaliza. Porque no son sujetos de la democracia, no expresan otros proyectos porque en esta perspectiva esos otros proyectos simplemente no existen. Los sujetos autorizados a expresarse en la democracia pospolítica son los que integran el consenso neoliberal y esa es la operación más audaz, a mi juicio, de este régimen discursivo, superponer democracia y neoliberalismo; o sea, fuera de esa superposición no queda nada. Lo podemos encontrar bajo distintas denominaciones: Germán Cano, filósofo español, llama a ese afuera de la pospolítica el "desecho", inclusive cuenta una anécdota de cuando las fuerzas represivas madrileñas fueron a desalojar el $15 \mathrm{M}$ en la Puerta del Sol. La primera línea de esas fuerzas represivas eran los camiones para recolectar basura y para limpiar, es decir había un desecho ahí que había que eliminar; Slavoj Žižek le llama "excremento", eso que está afuera y que efectivamente en ese diseño pospolítico no puede aparecer como otro proyecto, aparece como un sobrante, como un desecho, como un excremento, como algo que, efectivamente, hay que retirar.

Entonces hay una creciente autorización del uso de la violencia contra esos sujetos que resisten o directamente no pueden ser absorbidos por ese orden pospolítico.

¿Cómo construye la pospolítica las identidades a estigmatizar, segregar o reprimir? De muchos modos, pero yo voy a tomar una en especial porque estamos tomando como disparador este spot de los pizzeros sorprendidos de Ingeniero Maschwitz. La pizzera 
REVCOM | ISSN 2451-7836 | Año 4, \#8 | mayo de 2019 | Encuentros | e005

sorprendida, comenta como otra de las cosas que aparecen en el spot: "si todos trabajamos, todos avanzamos; si no trabajamos y lo único que hacemos es criticar, es como muy difícil salir adelante". En esos días también, Danilo, el dueño de una parrilla en San Nicolás estalló en llanto cuando un piquete frente a su local supuestamente le impidió trabajar; el Presidente escribió en Facebook sobre Danilo al día siguiente y dijo: "El martes los argentinos nos conmocionamos al verlo llorar a Danilo; él es un trabajador como tantos otros que la está peleando en este momento difícil y que sólo pide que lo dejen trabajar". El Presidente visita o llama por teléfono a estos trabajadores esforzados, es decir, esa identidad privilegiada de la pospolítica que delimita por contraste a los que hay que aislar, estigmatizar, segregar y, eventualmente, reprimir: son lo que no trabajan y los que no dejan trabajar. Por eso, Mauricio Macri aparece en estas escenas cotidianas y en estos spot como una especie de superhéroe que se indigna y acude en defensa de los que quieren trabajar pero otros no lo dejan o de los que trabajan a pesar de todas las adversidades y son agredidos por ello.

Dice Durán Barba: "Roberto Baradel es un líder docente que nunca dicta clases y se dedica a impedir que los maestros lo hagan", o sea, impide que otros trabajen. El trabajador neoliberal es aquel es interferido por los que no quieren trabajar y ¿quiénes son los que interfieren a ese trabajador neoliberal que quiere trabajar? Sindicalistas, piqueteros, militantes, todos ellos asociados a una identidad de base que son los "vagos", los que no quieren trabajar. Estas son algunas de las identidades que la maquinaria de comunicación oficial coloca como destinatarios del odio, son lo que se manifiestan en defensa de sus derechos; el contraste es claro: por un lado, los que reclaman trabajar con derechos, por el otro lado, los que renuncian a ellos.

En ese sentido, en la perspectiva de la pospolítica, el problema de este país es el exceso de derechos; entonces hay ahí dos proyectos: uno los promueve a los derechos, el otro propone eliminarlos, por supuesto no lo dice abiertamente. Pero de estos dos proyectos sólo uno de estos es reconocido, porque para que exista el proyecto único el otro tiene que ser suprimido, tiene que ser transformado en exceso, en sobrante. ¿Cuál es la solución? Una de las soluciones es, entonces, que el trabajo ocupe la totalidad del espacio que hoy tienen la política y el sindicalismo: las calles, las fábricas, las universidades deben quedar libres de política, y esos espacios vacíos deben ser ocupados por el trabajo; porque es la política la que impide el despegue y el éxito del país.

La pospolítica entonces es ese territorio protagonizado o por un trabajador explotado o 
REVCOM | ISSN 2451-7836 | Año 4, \#8 | mayo de 2019 | Encuentros | e005

por un emprendedor que supuestamente se autoexplota. Todos los otros sujetos pueden ser objeto de estigmatización, segregación, puestos fuera de la ley y, a veces como sabemos, reprimidos. Entonces, ahí se arma una serie discursiva, a mi juicio sigue teniendo capacidad de articular ese treinta por ciento que Cambiemos todavía retiene que no es poco, en donde los corruptos, los que acceden a planes sociales sin trabajar, los que obtuvieron jubilaciones sin aportes, los que ejercen derechos excesivos (docentes o empleados del Estado), los sindicalistas, los piqueteros, los militantes, los delincuentes, las barras bravas, los narcotraficantes del menudeo obtienen ingresos por fuera del trabajo, son los que se benefician injustamente con relación a los que ponen todo su esfuerzo y todo su tiempo en trabajar. En esta concepción, el trabajo sin derechos es el único distribuidor legítimo de ingresos; fíjense qué paradoja: los grandes exponentes del gran capital internacional y financiero son los que fijan de algún modo las características del trabajo legítimo.

¿Por qué? Porque el neoliberalismo no niega el trabajo, por el contrario, intenta colocar al trabajo con una identidad privilegiada pero a un tipo específico de trabajo: el trabajo sin derechos. El neoliberalismo busca la representación de un trabajador que acepta someterse a la lógica del capital y por lo tanto desiste de la obtención de derechos; el trabajador neoliberal es el que acepta perder, ese que está en la mitología del discurso oficial que se esfuerza de sol a sol sin pedir nada a cambio, casi como un patriota extremo. El máximo grado de neoliberalismo es el patriotismo, es una inversión discursiva muy fuerte. Por eso, en esta línea discursiva el estado populista es injusto con los que se esfuerzan comparado con los que obtienen sus ingresos sin esforzarse; sería como que el neoliberalismo viene a hacer justicia por los que trabajan mucho, y eso que el neoliberalismo efectivamente castiga, desiguala por decirlo de algún modo.

El contraste más extremo con un empleado esforzado es el "vago", el que directamente no trabaja y este discurso tiene lógica continental: Bolsonaro en Brasil, ejemplos de sus afirmaciones. Es la idea de que está como un exceso, algo que sobra y que requiere ser eliminado. Por eso, dos días después de su expedición al Calzone de la Nona el Presidente posteó con relación a los pizzeros emprendedores: "Luego de publicar el video de mi visita en Facebook, comenzaron a recibir agresiones en su página, aparecieron mensajes con lenguaje de odio deseándoles que les vaya mal, insultos y textos humillantes a esta pareja que solo quiere trabajar y crecer con su propio negocio. El único antídoto ante este veneno social que persigue inocentes es mantenerse unidos, tenemos que aislar a las personas envilecidas que 
REVCOM | ISSN 2451-7836 | Año 4, \#8 | mayo de 2019 | Encuentros | e005

buscan el fracaso de los demás". Hubo una discusión aquí porque algunos perspicaces lectores descubrieron que la frase "veneno social" y "personas envilecidas" figuran en un párrafo del libro Mi Lucha de Hitler. De todos modos, a mí me parece que si hay un autoritarismo en Cambiemos, y yo creo que lo hay, no es tanto porque utilice esta frase de Hitler que obedece más seguramente a alguna lectura de algún asesor del Presidente, sino que su componente autoritario le deviene de la concepción global que representa, porque la pospolítica de algún modo es autoritaria porque todo lo que no está colocado en el consenso, en ese proyecto único, está colocado como desecho, ahí es autoritario, y es depredador (dice Alejandra), o sea, a eso que aísla, a eso que pone a un costado, depreda.

La pospolítica es autoritaria en algún sentido porque funciona por estigmatización, segregación y represión de aquellos que desafían la existencia de ese discurso único. Dice Durán Barba y no tiene desperdicio: "En estos días hubo un aluvión de dólares húmedos en la City que probablemente vienen de valijas enterradas y sirven para financiar las movilizaciones populares que pretender desestabilizar al Gobierno". Es increíble pero esto está escrito. Búsquenlo. Continúa: "Hay mucho dinero húmedo financiando la protesta. Es muy caro organizar ollas populares en el centro de la Ciudad, porque se necesita transportar comida, ollas y la gente que vaya a comer; es un costoso acto de circo para agitar, ¿quién pone tanto dinero?" se pregunta Durán Barba. Este es el eslabón final: el que conecta el dinero de la corrupción enterrado en bóvedas en el sur (ustedes saben toda la mitología mediática construida) con la política en las calles y las identidades estigmatizables: piqueteros, militantes, sindicalistas; es decir, hay que eliminar todo junto: la política, el sindicalismo, la corrupción, es parte de un mismo combo porque de algún modo están todos fuera de la ley; en su lugar deben quedar los argentinos y argentinas que trabajan de sol a sol, es decir, los que se esfuerzan por ese país que todos nos merecemos.

Quiero hacer un pequeño desvío hacia esto de Durán Barba, dice por ejemplo: "La historia de Daniel Muñoz, secretario de Néstor Kirchner, que fabricó bolsos para quedarse con una porción del dinero que empacaba para su jefe". Después habla varias veces del avión presidencial que llevaba decenas de bolsos. El destino de ese dinero se sabe que fue robado entre ellos: los cómplices que ayudaban a ocultarlo saquearon los depósitos, dice. Toda una cuestión que a mí me parece interesante hacer una pequeña recorrida por los procedimientos de construcción de verdades que hay aquí, que atraviesan por supuesto los lenguajes judiciales y mediáticos. Porque acá un objeto que no existe deviene a existente por otro que a 
REVCOM | ISSN 2451-7836 | Año 4, \#8 | mayo de 2019 | Encuentros | e005

la vez tampoco existe: o sea, habla de bolsos y habla de valijas enterradas que no existen como referencia real para hablar de otro elemento que no existe que es el dinero enterrado; el dinero que no aparece existe a través de los bolsos, valijas y bóvedas que tampoco aparecen. Lo que no existe es creado por lo que no existe. Las cosas no existentes se dan "estatuto de existencia" entre sí: dinero, bolsos, valijas, bóvedas, todo toma materialidad en el vacío total de referencias. Las cadenas de pruebas entonces son series de palabras que nunca encuentran su objeto; términos que sólo existen en el discurso pero, hasta ahora, nunca encuentran su dimensión específicamente referencial, salvo en el caso de los bolsos de López, por eso cada vez que el discurso les entra en crisis vuelven; hay una lógica aquí: cada vez que este discurso sin referencia les entra en crisis porque mandaron retroexcavadoras al sur y no encontraron y destruyeron casas para ver si había bóvedas y no las encuentran, entonces lo que aparece es la importación de cuotas del pasado y ahí viene López, que es la única referencia que ha quedado instalada.

Se trata de un nuevo lenguaje que funciona como una interioridad: la cadena relacional que hace existente lo inexistente deviene de la existencia de otro objeto que tampoco existe. Por eso, corrupción es lo que estos lenguajes dicen que es corrupción; con esos discursos que efectivamente se autosostienen, son autosuficientes, los jueces y los medios salen a denunciar y a producir hechos; discursos que se basan en referentes que no aparecen o que incluso han desaparecido, por ejemplo los cuadernos que existen como fotocopias, no como su objeto original. Entonces, la existencia de un objeto en estos nuevos dispositivos de verdad existen también a través de cómo nos cuentan la historia de su desaparición: los cuadernos existen porque nos cuentan el modo en el que desaparecieron, quemados por el chofer en un lugar, etcétera. Hay un relato que va contando la desaparición y, a partir de relatar la desaparición, van existiendo.

Además, por los procedimientos de estas discursividades, las cosas no existen cuando se las encuentran sino cuando se las buscan: la repetición de lo que permanece en estado de búsqueda lo hace existente. La paradoja de estos procedimientos de verdad es que mientras más tarda en aparecer lo que se busca, más existencia toma. Lo voy repitiendo y lo hago existente. En ese 30 por ciento que hoy tiene Macri (aunque no es un dato empírico) da toda la impresión de que estos elementos que se dan existencia entre sí existen como referentes; por la magia de esta discursividad, elementos que no tienen existencia se la dan entre sí y, en algún momento, eso que no tiene referencia, pasa a tenerla. 
Fabiana Martínez: En primer lugar, quiero agradecer a los organizadores del evento, no solo por la invitación, sino por el armado mismo del panel. Los que hacemos análisis del discurso o estamos trabajando desde perspectivas semióticas, sabemos que es una disciplina que tiene algo que decir sobre nuestra contemporaneidad. En segundo lugar, gracias a los que están acá escuchando; y en tercer lugar: los últimos no serán los primeros, los últimos serán los más breves

Es una presentación que está en total consonancia con lo que han planteado los trabajos anteriores. Lo primero que quiero decir, es que cuando empecé a pensar este trabajo, la cuestión primera sobre la que me pregunté es: sujeto y discurso. Cuando uno está trabajando desde teorías discursivas, ¿qué noción de sujeto tiene, que no deje afuera la ideología, el cuerpo, los rituales, los aparatos del estado en todas sus formas? Decidí que el eje del trabajo fuera la noción de interpelación subjetivante, no literalmente como la planteó Althusser, sino como ha venido siendo recuperada después por el posfundamento, entendiendo la interpelación subjetivante, no al sujeto de carne y hueso, sino más bien a esos procesos de devenir sujeto que van tramándose en las dimensiones del imaginario, de lo simbólico, de lo discursivo, a esa idea de que ser sujeto es también de alguna forma identificarse con una llamada. Pensar la subjetividad, también como un conjunto de llamadas que estarían disponibles en el discurso social y que la existencia social, aun hasta en términos de Butler, advenimos como subjetividad en la medida en que nos identificamos con alguna de estas llamadas que están disponibles en un momento histórico dado, tramadas en distintas hegemonías que son políticas y también discursivas. Entonces, la idea de la llamada o de la identificación es también la idea de que esto es siempre incompleto, la idea de un sujeto que nunca tiene una sutura final es una idea políticamente emancipatoria porque significa que podemos desidentificarnos de las formas de definirnos, operaciones que no es que sean conscientes, son tramadas en múltiples niveles, para poder provocar identificaciones con nuevos significantes.

A partir de esa definición, lo que quiero tratar de pensar es ¿cuál es la interpelación subjetivante que se define en el contexto de la hegemonía discursiva de Cambiemos? Es decir, estos discursos que han venido a definir las nuevas dominancias contemporáneas ¿qué figuras de subjetividad hacen predominar? Porque claramente como plantea Lewkowicz, cada época define para sí misma un determinado ideal de la subjetividad que es la que propone de manera 
REVCOM | ISSN 2451-7836 | Año 4, \#8 | mayo de 2019 | Encuentros | e005

dominante, no es necesariamente la que se realice exhaustivamente, porque si esto fuera así nunca habría un cambio. Siempre hay un exceso, siempre hay un resto, siempre hay algo que la llamada interpelativa subjetivante hegemónica no logra articular, ese exceso es el que trae el cambio después, trae la corrosión, la transformación, la subversión, porque propone la reformulación de los significantes dados.

Parto de la idea de que Cambiemos propone al sujeto hegemónico, al sujeto meritocrático, y parto de la idea de que para que sea hegemónico, de que para que el sujeto meritocrático ocupe posiciones hegemónicas, hay que desplazar a la periferia al sujeto militante, el sujeto militante es la articulación de la antigua, de la anterior, hegemonía política y discursiva, a la que podríamos designar hegemonía kirchnerista, pero que a veces no tiene nombre, porque es la hegemonía de los que pelearon, de los que militaron la lucha de género, las luchas por la memoria, las luchas por la verdad y la justicia, es decir, estas subjetividades no tienen solo nombre partidario, van correspondiendo a distintas series temáticas que se van presentando.

Entonces, parto de la idea de que hoy es hegemónico el sujeto meritocrático y está siendo desplazado a los bordes el sujeto militante (que esté desplazado a los bordes no significa que no exista, significa que resiste). También quisiera decir que esta reconfiguración topográfica no está aludiendo a cuerpos empíricos, sino que está aludiendo a discursos que están en tensión, y que tienen no solo dominancia sino construcciones aporéticas, tienen sus regularidades y también sus diferencias. De modo que cuando digo sujeto más bien estoy hablando de subjetividades que se ofrecen imágenes del sujeto, que se ofrecen desde los discursos.

No tengo tiempo acá para referir los rasgos que voy a describir a discursos concretos, pero quiero decir que para llegar a la categorización que voy a presentar he trabajado sobre muchas materialidades discursivas, desde ya todo lo que emana de los funcionarios de Cambiemos y de sus sitios de comunicación oficial, pero también he trabajado publicidades. No sé si ustedes recuerdan la publicidad de Chevrolet, que se llamaba "Meritocráticos en meritocracia", eso da una pista acerca de la dominancia que tiene ese tópico, porque no está solamente en la discursividad política, está atravesando a toda la discursividad social, y uno de los últimos materiales que trabajé, fue la aparición de Casero con su metáfora, su anécdota, su planteo, del Flan, que a mí me parece completamente sintomática del sujeto meritocrático. Así que yo abordo en mis análisis heterogeneidades discursivas a las que casi no voy a referir, sino 
REVCOM | ISSN 2451-7836 | Año 4, \#8 | mayo de 2019 | Encuentros | e005

que van a quedar como dos tipos ideales, pero bueno en todo caso si preguntan podemos profundizar.

Mi idea es entonces, que este sujeto meritocrático, también se hace hegemónico porque en toda la retórica de Cambiemos intenta convencernos de que tenemos que pensarnos sin Estado, es una figura que se vincula mucho a la semantización negativa de todas las instituciones y las posiciones de sujeto vinculadas a lo que ellos llaman la política clásica, que sería la política de los últimos años, 30 años democráticas, siempre viciada y contaminada de corrupción. Entonces mi idea es, en este trabajo, ya brevemente digamos, a esta altura de la mañana plantear cinco rasgos que emanan de las propias materialidades discursivas, no rasgos que yo inventé, cinco rasgos que caracterizarían a la subjetividad militante y que pongo en juego así de manera contrastiva con cinco rasgos que caracterizarían a las subjetividades meritocráticas. Insisto en que el sujeto meritocrático aparece en muchos lugares, en la campaña de Macri aparecía en la niña, bastante pobre que cultivaba rosas para venderlas y llegar a comprarse una bicicleta, y los chicos que ponen la pizzería también están encarnando ese ideal meritocrático que nos propone la discursividad hegemónica de Cambiemos.

Diciéndolo en síntesis, voy a plantear que el sujeto militante, que en otros términos sería el sujeto fiel a otra cosa que no es él, va a estar en primer lugar, en general va a definir su subjetividad en relación al Estado, o en relación a instituciones o instancias que uno podría considerar de la política, porque va a hacer un diagnóstico de lo que parte Arditi llamó "el reencantamiento de la política", no de la política limitada a lo que reconocemos como las instituciones de la democracia en el momento moderno, sino a la política entendida como un espacio para transformar nuestras propias condiciones de vida, simbólicas, materiales, en todos los niveles. Es decir, la política en un sentido amplio, como un espacio del hacer. El sujeto meritocrático, en cambio, va a entrar en polémica con este tópico, y en este punto va a tener dos características: la primera, es que se va a constituir desde retóricas profundamente antipolíticas, lo que planteaba recién Daniel, desde lecturas pospolíticas, y uno podría decir desde un desencantamiento total que viene bastante construido desde discursos que provienen del Estado y también de muchos medios de comunicación. Los medios de comunicación hay colaborado mucho en provocar el desencantamiento de las instancias políticas básicamente porque han hecho un equivalente total entre política y corrupción, no importa que se hable de las instituciones o de los actores, lo que importa es que la construcción total ha hecho una equivalencia plena, prácticamente hacer política es ser corrupto. Por eso el sujeto militante está 
REVCOM | ISSN 2451-7836 | Año 4, \#8 | mayo de 2019 | Encuentros | e005

en el lugar del estigma hoy, es casi un insulto desde este otro lado de la subjetividad hegemónica. $\mathrm{Y}$ el segundo rasgo del sujeto meritocrático es que como se desvincula de las instituciones se presenta siempre como un empresario de sí mismo, es un sujeto que ha incorporado de la tecnología de gubernamentalidad capitalista actual, y se presenta como dueño de sí, se hace a sí mismo, no depende de nadie, se presente a sí mismo como un capital potencial permanente frente a las adversidades, los fracasos, el perpetuo diferimiento de la promesa económica de Cambiemos, y por lo tanto, su vínculo, como es un sujeto que se hace a sí mismo, no se plantea en un espacio público, sino que es un sujeto generalmente escenificado en un espacio doméstico, en lugar de su trabajo, el lugar de su casa, el pequeño lugar doméstico donde él sueña su sueño individual.

La segunda característica que le atribuyo al sujeto militante es que es el sujeto que se construye a partir de una demanda. La demanda, no solamente es un acto político, es también un acto discursivo, un acto lingüístico, no hay demanda si no hay formulación de que es lo que se pide, y el sujeto viene como un devenir de esa demanda, la subjetividad política deviene vinculada a la demanda, ¿qué es lo que sucede con el sujeto meritocrático?, no va a demandar, porque ha diluido la instancia del Estado, o cualquier otra instancia política como espacio legítimo para pedir, y porque se ha recluido en sí mismo, es un sujeto autoresponsable, es un sujeto que responde por sí, y por lo tanto, la demanda va a empezar a ser semantizada negativamente, e incluso va a empezar a ser forcluida, es decir, no solo que demandar es malo, demandar no corresponde. La locución de Casero en ese programa televisivo, tiene que ver con eso, se te quemó la casa, tenés muchísimos hijos, bueno, no podés pedir nada, no podés pedir ni flan ni nada, cualquier cosa que pidas va a ser catalogada como un exceso. Eso ya es una configuración simbólica donde queda como desubicado el acto de la demanda, y el acto de la demanda es siempre profundamente político. Otra cosa, es que no hay demanda porque no hay nominación de la catástrofe, que es exactamente lo que también ejemplifica esta anécdota, una casa incendiada y no hay ningún discurso ni enunciado ni del daño ni de la solidaridad, ni del reconocimiento de ese daño. Estamos viviendo un momento en que la catástrofe no es nominada, no es reconocida, no se inscribe simbólicamente en los discursos hegemónicos, y en consecuencia tampoco se puede entonces demandar. Casero tuvo que literalizar su anécdota, y luego tuvo que decir que el flan, me parece que lo tuvo que decir porque Cambiemos no lo entendió, dijo el flan es Baradel pidiendo el $21 \%$, todo esto dicho en un tono jocoso donde el humor se vuelve bastante cínico en cierta 
REVCOM | ISSN 2451-7836 | Año 4, \#8 | mayo de 2019 | Encuentros | e005

manera, literalmente, sobre una familia numerosa que se le quemó la casa.

El tercer punto, es que en la subjetividad militante se van inscribir en discursos donde se va a configurar un pueblo dañado, no un pueblo como un sujeto empírico, sino como una articulación de partes, va a haber colectivo, va a haber una identidad populista a la que se va a vincular con un daño, desde hijos a quien se había privado de la memoria hasta el movimiento piquetero a quien se lo había privado del trabajo, hasta a las mujeres que demanda hoy a quienes se les ha privado de un aborto en condiciones no clandestinas, todas estas discursividades son militantes, porque tematizan el colectivo y tematizan el daño de ese colectivo. En el caso de subjetividades que proponen sujetos meritocráticos, no va a haber ningún registro de lo colectivo, no va a haber ningún registro de pueblo, solo hay singularidades porque lo que las discursividades vinculadas a los sujetos meritocráticos tematizan es el poder pastoral, es el gobierno de lo Uno, es el sujeto soñando en su espacio doméstico, porque eso es lo que gestiona el pastor, el sueño individual de cada oveja. Los timbreos son una modalidad comunicacional totalmente vinculada a esto, y no solo los timbreos sino también fragmentos como "Mauricio y vos" y las construcciones tan simétricas que él hace en algunos spots audiovisuales, el timbreo no está muy lejos de la visita a la pizzería, es la misma lógica. Hay una pura lógica de la diferencia que gestiona sujetos meritocráticos, cada uno salvándose a sí mismo, en la medida en que tengamos una pura lógica de la diferencia, no vamos a tener ningún equivalencia metonímica entre las demandas, es decir, va a ser muy difícil construir la cadena de solidaridad, acá estoy utilizando algunas categorías de Laclau, pero que tienen que ver con esta dominancia donde lo que gana el sujeto, el discurso del poder, es esto, la promoción de la incapacidad de articulación de una demanda con otra, y de un daño con otro, la construcción de un colectivo.

El cuarto elemento es que el imaginario efectivo que impulsa al sujeto militante es un imaginario de la solidaridad, y hay claramente en estos discursos una pregunta por la igualdad con el otro, la igualdad también es un término muy metafórico, pero bueno está allí presente. En el sujeto metafórico no hay pregunta por la igualdad, porque la igualdad también es una categoría forcluida, si dependemos de nosotros mismos, pues simplemente cada uno tiene lo que se merece, entonces en el lenguaje del mérito, no habría exactamente injusticia, habría desigualdades que se fundamentan a sí mismas, porque cada uno está en el lugar que se merece. Por eso, el tópico "los pobres, son pobres porque quieren" que se había vuelto un tópico un tanto periférico en la hegemonía anterior, retorna y en este momento es un tópico 
REVCOM | ISSN 2451-7836 | Año 4, \#8 | mayo de 2019 | Encuentros | e005

central, es posible afirmar ese tópico porque el sujeto central es el sujeto meritocrático, el que se instituye como norma es ese, todos los otros son desvíos.

El último componente, que quiero mencionar, es que el sujeto militante es un sujeto de la memoria, es un sujeto que está vinculado a las retóricas que pidieron justicia, que pidieron verdad, que pidieron memoria, que permitieron categorizar la dictadura como un genocidio, y que provocaron como efecto performativo los juicios. No es necesario que militen hijos, es el sujeto que marchó contra el 2x1, es el sujeto que se movilizó para escuchar los juicios de la sentencia, es un sujeto que inscribe su subjetividad en una densa trama simbólica que remite un pasado relatado de cierta manera, y no es necesario tampoco que este pasado esté presente de manera lingüística, el pañuelo verde es una cita del pañuelo blanco, no hubiera estado nunca en quienes estuvieron en contra de la ley de legalización del aborto, no hubieran puesto un pañuelo de hecho pusieron una escarapela, que es el signo de lo uno, de la eliminación de la grieta y es la expulsión del litigio del campo político. En cambio el sujeto meritocrático, como acabamos de ver en el ejemplo de los pizzeros, yo te lo robo así todo lleva menos tiempo, ¿qué es lo que uno ve? Que el sujeto meritocrático no da cuenta del pasado, inscribe su subjetividad en el futuro, en un futuro que siempre aparece como esperanzador que como efecto retroactivo podría desparramar cierta alegría sobre a pesar de los obstáculos en el presente, pero es un sujeto completamente articulado hacia el futuro, esa es la discursividad, esa es la frontera temporal que también es hegemónica en la discursividad de Cambiemos, el pasado aparece como una obstrucción, aparece como un obstáculo, tenemos que superar ese pasado molesto para ir todos hacia adelante. No obstante, ellos, colocan como categoría de inteligibilidad de su propio fracaso la idea de la pesada herencia, es decir, hay usos del pasado que van a distintas estrategias, pero básicamente el pasado pensado colectivo y socialmente es un pasado que no es pertinente en el caso de las subjetividades meritocráticas cuando éstas se hacen hegemónicas.

Para cerrar, el sujeto meritocrático es un sujeto proclive al odio social, es un sujeto que rápidamente se inscribe en retóricas del insulto, en retóricas de la denegación, es el sujeto que vimos en el barrio de Nueva Córdoba cuando se autocuarteló la policía, porque es un sujeto que ha hecho una frontera fuerte entre sí mismo y los otros, esos que aparecen como el exceso, como los militantes, como los que no son meritocráticos, como los que se quedaron afuera porque se lo merecen, porque no hicieron los suficiente de su vida. Frente a ese sujeto, no hay nunca un discurso de solidaridad, lo que hay es un discurso de odio, la base de ese 


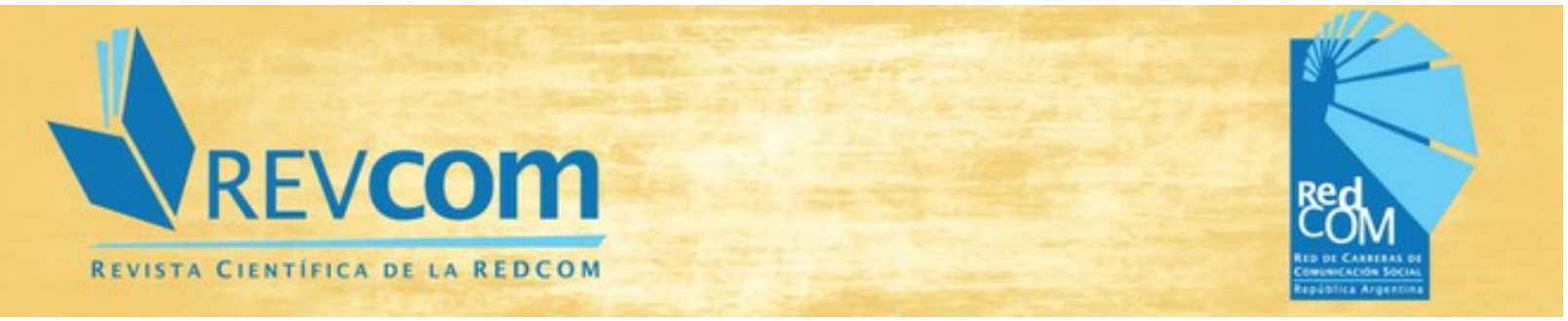

REVCOM | ISSN 2451-7836 | Año 4, \#8 | mayo de 2019 | Encuentros | e005

discurso de odio es un sentimiento de amenaza, la amenaza y el odio son los dos sentimientos que utiliza el Neoliberalismo cuando empieza a gobernar por precarización generalizada, es decir, no va a gobernar por una expansión de los derechos, sino que por una extirpación aún de las condiciones materiales mínimas para mantener la vida vivible físicamente.

Quiero decir que también patéticamente el sujeto meritocrático está siempre muy cercano a un lenguaje del odio que se puede ver cada vez más en las redes, sobre todo, quizás no tanto en los medios de comunicación donde hay otros filtros o tamices, pero se puede ver en las redes este odio social que irrumpe y que se tracciona desde una configuración que no es sencilla. Lo que quería trabajar era la destitución de un sujeto propio.

Artículo recibido el 25-04-2019 | Evaluado y aprobado por el Comité Editorial el 10-05-2019 | Publicado 26-05-2019

http://perio.unlp.edu.ar/ojs/index.php/revcom/ Esta obra está bajo una Licencia Creative Commons Atribución-NoComercial-SinDerivar 4.0 Internacional 